VIVIANE MICELI SILVA QUEIROZ

\title{
ESTUDO EXPERIMENTAL DO ESCOAMENTOE E DA CONCENTRAÇÃO DE MISTURA NO PROCESSO DE FILTRAÇÃO TANGENCIAL DE SUSPENSÕES MACROMOLECULARES
}

Dissertação apresentada à Escola de Engenharia de São Carlos da Universidade de São Paulo, como parte dos requisitos para a obtenção do Título de Mestre em Engenharia Mecânica.

Orientador: Prof. Dr. Sérgio Rodrigues Fontes

São Carlos 
Dedico este trabalho aos meus pais, Laércio Ferreira e Silva, Maria de Lourdes Miceli e Silva, que sempre me apoiaram nos momentos difíceis e aos quais eu devo minha eterna gratidão por tudo que me proporcionaram. Dedico também ao meu marido, Rafael Queiroz, pela ajuda e compreensão. A minha irmã Valéria, minha sobrinha Vitória e meu cunhado Fábio que acompanharam toda essa trajetória. Aos meus avós Héllio Miceli (“in memorian”) e Maria Eugênia Lourdes Zocco Miceli. 


\section{AGRADECIMENTOS}

Alcancei mais uma etapa da minha vida e só consegui realizá-la, com a ajuda de pessoas que merecem os meus agradecimentos.

Gostaria de agradecer, primeiramente, a Deus pela oportunidade, força e saúde que me proporcionou para realizar este trabalho. Agradeço ao Prof. Dr. Sérgio Rodrigues Fontes pela orientação, dedicação, generosidade e total atenção na condução desta dissertação.

Ao Dr. Odílio e Dr. Colnago, pesquisadores da EMBRAPA, por colocar a disposição os equipamentos desta unidade, pelo apoio e sugestões na confecção do trabalho. Ao Prof. Dr. Moreira a ao Dr. Odílio pela participação no exame de Qualificação.

Aos técnicos do laboratório de termodinâmica e fluidos, Jorge, Hélio, Luchesi, aos dois Roberto e Donizeti pela ajuda e eficiência na montagem e preparação do equipamento para a realização de experimentos.

À Universidade de São Paulo por colocar a minha disposição sua estrutura, a todos os professores e funcionários do departamento de Engenharia Mecânica que colaboraram de alguma forma para minha formação.

Sou grata à CAPES, à CNPq e à FAPESP pelo auxílio financeiro desta pesquisa.

Às minhas grandes amigas Cris, Roberta, Tati e Solange que, algumas delas, mesmo distante estiveram presentes de alguma maneira.

Aos meus amigos que conviveram comigo durante estes dois anos de pósgraduação, em especial a Paula, Ana Paula, Selma, Cecília, Graziela, Paulo, Erica, Juliana. 


\section{RESUMO}

Queiroz, V. M. S. (2004). Estudo experimental do escoamento e da concentração de mistura no processo de filtração tangencial de suspensões macromoleculares. Dissertação (mestrado) - Escola de Engenharia de São Carlos, Universidade de São Paulo, São Carlos, 2004.

O processo de microfiltração tangencial com membranas tubulares inorgânicas e tubos microporosos, respectivamente de origem importada e nacional, foi investigado tendose como objeto de separação as misturas macromoleculares preparadas com os agentes polissacarídeos gomas Xantana e Guar em suspensão aquosa. São evidenciados neste processo os efeitos de sinergia compreendidos nas misturas elaboradas puras e em diferentes proporções, na concentração final de 1000 ppm. A investigação experimental acompanha o comportamento reológico de cada mistura ao longo do processo e os resultados foram investigados a partir de propriedades físico-químicas relevantes como: concentração de Carbono Orgânico Total (Total Organic Carbon - TOC) e análise de absorbância no espectômetro de infravermelho. Resultados de TOC indicaram que em apenas um meio filtrante tubular microporoso $(\mathrm{C} 1 \mathrm{~T}+)$, o desempenho do processo na retenção dos polissacarídeos foi acima de 90\%, em relação ao processo com a membrana comercial importada cuja retenção de TOC foi da ordem de $80 \%$. De acordo com as análises de absorbância, conclui-se que as membranas com tamanho do poro nominal de 0,2 $\mu \mathrm{m}$ e $0,4 \mu \mathrm{m}$ tiveram uma retenção mais eficiente do que os tubos microporosos em estudo. A temperatura foi um parâmetro significativo, pois a retenção, na maioria dos casos, foi maior na temperatura de $25^{\circ} \mathrm{C}$, independente da pressão e da velocidade média. $\mathrm{Na}$ análise dos procedimentos envolvendo cada mistura, foi constatada a boa sinergia entre as gomas, sem modificação de estrutura (formação de gel) ou fenômenos de superfície que impedissem o processo de microfiltração. A vazão transmembrana das misturas ficou limitada entre os máximos valores para mistura pura de Xantana e mínimos para Guar. Todas as misturas apresentaram comportamento pseudoplástico, sem mudanças na reologia, reforçando a adequada sinergia quanto a este aspecto.

Palavras-chave: Filtração tangencial; microfiltração, suspensões, goma Guar, goma Xantana. 


\section{ABSTRACT}

Queiroz, V. M. S. (2004). Experimental study of the flow and mixture concentration in the cross-flow filtration of macromolecular suspensions. M.Sc. Dissertation - Escola de Engenharia de São Carlos, Universidade de São Paulo, São Carlos, 2003.

The present dissertation reports cross-flow microfiltration with national and imported inorganic tubular membranes and microporous tubes. The object of separation is the macromolecular mixtures prepared with polysaccharide agents Xanthan and Guar gum in aqueous solution. The process shows the synergism effects in pure and different mixture proportions, with $1000 \mathrm{ppm}$ final concentration. The experiments established the rheologic behaviour of each mixture along the process and significant physical and chemical properties, such as Total Organic Carbon concentration (TOC) and absorbency analysis in infrared spectrometer were analyzed. TOC retention shows that only one microporous tubular filtering medium $(\mathrm{C} 1 \mathrm{~T}+$ ) had better performance (retention $>90 \%$ ) than the imported commercial membrane (retention about 80\%). Absorbency analysis show a better retention efficiency of membranes with pore size of $0,2 \mu \mathrm{m}$ and $0,4 \mu \mathrm{m}$ than microporous tube. The temperature was a significant parameter, as the better retention was obtained at $25^{\circ} \mathrm{C}$, independently of pressure and mean velocity. There is good synergism between Xanthan and Guar gums without structure modifications or surface phenomena that would impede the microfiltration process. The transmembrane flux of proportional mixtures has been limited between maximum values of pure Xanthan and minimum values of pure Guar mixtures. All mixtures have pseudoplastic behaviour, without changes in rheology, intensifying the good synergism.

Keywords: Cross-flow filtration; microfiltration, suspensions, Guar gum, Xanthan gum. 


\section{LISTA DE FIGURAS}

FIGURA 2.1 - Estrutura do polissacarídeo extracelular da X. Campestris .............. 23

FIGURA 2.2 - Estrutura molecular da goma Guar .............................................. 25

FIGURA 2.3 - Reograma do diversos tipos de fluidos .......................................... 29

FIGURA 2.4 - Classificação geral do comportamente reológico dos fluidos ......... 29

FIGURA 2.5 - Microfiltração perpendicular............................................................. 36

FIGURA 2.6 - Microfiltração tangencial ……....................................................... 37

FIGURA 2.7 - Perfil de concentração de componentes preferencialmente permeáveis sob regime permanente ............................................. 50

FIGURA 2.8 - Perfil de concentração dos componentes retidos sob

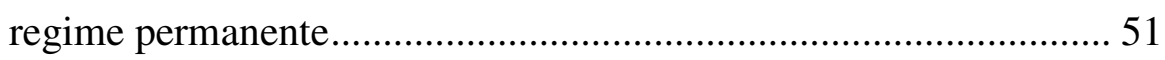

FIGURA 3.1 - Foto do equipamento experimental ................................................. 55

FIGURA 4.1 - (a) Membrana monocanal com tamanho do poro de $0.2 \mu \mathrm{m}$ à $25^{\circ} \mathrm{C}$; (b) Membrana monocanal com tamanho do poro de $0.2 \mu \mathrm{m}$ a $40^{\circ} \mathrm{C}$

FIGURA 4.2 - (a) Membrana monocanal com tamanho do poro de $0.4 \mu \mathrm{m}$ à $25^{\circ} \mathrm{C}$; (b) Membrana monocanal com tamanho do poro de $0.4 \mu \mathrm{m}$ a $40^{\circ} \mathrm{C}$ 61

FIGURA 4.3 - (a) Membrana multicanal com tamanho do poro de $0.2 \mu \mathrm{m}$ à $25^{\circ} \mathrm{C}$; (b) Membrana multicanal com tamanho do poro de $0.2 \mu \mathrm{m}$ a $40^{\circ} \mathrm{C}$ 61

FIGURA 4.4 - (a) Tubo microporoso com tamanho do poro de $0.3 \mu \mathrm{m}$ à $25^{\circ} \mathrm{C}$; (b) Tubo microporoso com tamanho do poro de $0.3 \mu \mathrm{m}$ a $40^{\circ} \mathrm{C}$ 62

FIGURA 4.5 - (a) Membrana monocanal com tamanho do poro de $0.4 \mu \mathrm{m}$

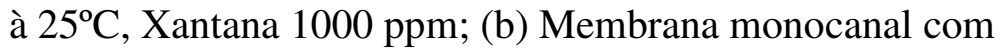
tamanho do poro de $0.4 \mu \mathrm{m}$ a $25^{\circ} \mathrm{C}$, Guar $1000 \mathrm{ppm}$ 63

FIGURA 4.6 - (a) Membrana monocanal com tamanho do poro de $0.4 \mu \mathrm{m}$ à $25^{\circ} \mathrm{C}$, mistura de Xantana 500 ppm e Guar 500 ppm;

(b) Tubo microporoso (C1T-) a $25^{\circ} \mathrm{C}$ com Xantana $1000 \mathrm{ppm}$. 
FIGURA 4.7 - (a) Tubo microporoso (C2T-) a 25ㅇ com Xantana 1000 ppm;

(b) Tubo microporoso $(\mathrm{C} 2 \mathrm{~T}+)$ a $25^{\circ} \mathrm{C}$ com Xantana $1000 \mathrm{ppm}$.

Variação de pressão e velocidade 65

FIGURA 4.8 - (a) Tubo microporoso (C3T-) a 25ㅇ com Xantana 1000 ppm;

(b) Tubo microporoso $(\mathrm{C} 4 \mathrm{~T}+)$ a $25^{\circ} \mathrm{C}$ com Xantana $1000 \mathrm{ppm}$

Variação de pressão e velocidade 66

FIGURA 4.9 - (a) Membrana monocanal com tamanho do poro de $0.2 \mu \mathrm{m}$

a $25^{\circ} \mathrm{C}$; (b) Membrana monocanal com tamanho do poro

de $0.2 \mu \mathrm{m}$ a $40^{\circ} \mathrm{C}$. Adimensional.

FIGURA 4.10 - (a) Membrana monocanal com tamanho do poro de $0.4 \mu \mathrm{m}$

a $25^{\circ} \mathrm{C}$; (b) Membrana monocanal com tamanho do poro

de $0.4 \mu \mathrm{m}$ a $40^{\circ} \mathrm{C}$. Adimensional.

FIGURA 4.11 - (a) Membrana multicanal com tamanho do poro de $0.2 \mu \mathrm{m}$

a $25^{\circ} \mathrm{C}$; (b) Membrana multicanal com tamanho do poro

de $0.2 \mu \mathrm{m}$ a $40^{\circ} \mathrm{C}$. Adimensional 68

FIGURA 4.12 - (a) Tubo microporoso com poro de $0.3 \mu \mathrm{m}$ a $25^{\circ} \mathrm{C}$; (b) Tubo microporoso com poro de $0.3 \mu \mathrm{m}$ a $40^{\circ} \mathrm{C}$. Adimensional. 68

FIGURA 4.13 - (a) Membrana monocanal com tamanho do poro de $0.4 \mu \mathrm{m}$

a $25^{\circ} \mathrm{C}$, Xantana $1000 \mathrm{ppm}$; (b) Membrana monocanal com tamanho do poro de $0.4 \mu \mathrm{m}$ a $25^{\circ} \mathrm{C}$, Guar $1000 \mathrm{ppm}$.

Variação de pressão e velocidade. Adimensional. 69

FIGURA 4.14 - (a) Membrana monocanal com tamanho do poro de $0.4 \mu \mathrm{m}$

a $25^{\circ} \mathrm{C}$, mistura de Xantana 500 ppm e Guar 500 ppm;

(b) Tubo microporoso (C1T-) a $25^{\circ} \mathrm{C}$ com Xantana $1000 \mathrm{ppm}$.

Variação de pressão e velocidade. Adimensional. 69

FIGURA 4.15 - (a) Tubo microporoso (C2T-) a $25^{\circ} \mathrm{C}$ com Xantana 1000 ppm;

(b) Tubo microporoso $(\mathrm{C} 2 \mathrm{~T}+)$ a $25^{\circ} \mathrm{C}$ com Xantana $1000 \mathrm{ppm}$

Variação de pressão e velocidade. Adimensional. 70

FIGURA 4.16 - (a) Tubo microporoso (C3T-) a $25^{\circ} \mathrm{C}$ com Xantana 1000 ppm;

(b) Tubo microporoso $(\mathrm{C} 4 \mathrm{~T}+)$ a $25^{\circ} \mathrm{C}$ com Xantana $1000 \mathrm{ppm}$.

Variação de pressão e velocidade. Adimensional. 70 
FIGURA 4.17 - (a) Membrana monocanal com tamanho do poro de $0.4 \mu \mathrm{m}$ à $25^{\circ} \mathrm{C}$, Xantana 1000 ppm; (b) Membrana monocanal com tamanho do poro de $0.4 \mu \mathrm{m}$ a $25^{\circ} \mathrm{C}$, Guar $1000 \mathrm{ppm}$. Variação de pressão e velocidade Adimensional

FIGURA 4.18 - (a) Membrana monocanal com tamanho do poro de $0.4 \mu \mathrm{m}$ a $25^{\circ} \mathrm{C}$, mistura de Xantana 500 ppm e Guar 500 ppm;

(b) Tubo microporoso (C1T-) a $25^{\circ} \mathrm{C}$ com Xantana $1000 \mathrm{ppm}$.

Variação de pressão e velocidade. Adimensional. 71

FIGURA 4.19 - (a) Tubo microporoso (C2T-) a 25 ${ }^{\circ} \mathrm{C}$ com Xantana 1000 ppm;

(b) Tubo microporoso $(\mathrm{C} 2 \mathrm{~T}+)$ a $25^{\circ} \mathrm{C}$ com Xantana $1000 \mathrm{ppm}$.

Variação de pressão e velocidade. Adimensional. 72

FIGURA 4.20 - (a) Membrana monocanal com tamanho do poro de $0.2 \mu \mathrm{m}$

a $25^{\circ} \mathrm{C}$; (b) Membrana monocanal com tamanho do poro de $0.2 \mu \mathrm{m}$ a $40^{\circ} \mathrm{C}$. Adimensional. 73

FIGURA 4.21 - (a) Membrana monocanal com tamanho do poro de $0.4 \mu \mathrm{m}$ a $25^{\circ} \mathrm{C}$; (b) Membrana monocanal com tamanho do poro de $0.4 \mu \mathrm{m}$ a $40^{\circ} \mathrm{C}$. Adimensional. 74

FIGURA 4.22 - (a) Membrana multicanal com tamanho do poro de $0.2 \mu \mathrm{m}$ a $25^{\circ} \mathrm{C}$; (b) Membrana multicanal com tamanho do poro de $0.2 \mu \mathrm{m}$ a $40^{\circ} \mathrm{C}$. Adimensional. 74

FIGURA 4.23 - (a) Tubo microporoso com poro de $0.3 \mu \mathrm{m}$ a $25^{\circ} \mathrm{C}$;

(b) Tubo microporoso com poro de $0.3 \mu \mathrm{m}$ a $40^{\circ} \mathrm{C}$.

Adimensional. 75

FIGURA 4.24 - (a) Membrana monocanal com tamanho do poro de $0.4 \mu \mathrm{m}$ a $25^{\circ} \mathrm{C}$, Xantana $1000 \mathrm{ppm}$; (b) Membrana monocanal com tamanho do poro de $0.4 \mu \mathrm{m}$ a $25^{\circ} \mathrm{C}$, Guar $1000 \mathrm{ppm}$. Variação de pressão e velocidade. Adimensional. 76

FIGURA 4.25 - (a) Membrana monocanal com tamanho do poro de $0.4 \mu \mathrm{m}$ a $25^{\circ} \mathrm{C}$, mistura de Xantana 500 ppm e Guar 500 ppm;

b) Tubo microporoso (C1T-) a $25^{\circ} \mathrm{C}$ com Xantana $1000 \mathrm{ppm}$. Variação de pressão e velocidade. Adimensional. 
FIGURA 4.26 - (a) Tubo microporoso (C2T-) a 25ㅇ com Xantana 1000 ppm;

(b) Tubo microporoso (C3T-) a $25^{\circ} \mathrm{C}$ com Xantana $1000 \mathrm{ppm}$ Variação de pressão e velocidade. Adimensional.

FIGURA 4.27 - Índice de comportamento (n) para as temperaturas de $25^{\circ} \mathrm{C}$

e $40^{\circ} \mathrm{C}$ e em diferentes meios filtrantes no início e no

fim de cada experimento 78

FIGURA 4.28 - Resultados da análise do permeado pela técnica de infravermelho para experimentos realizados com membranas monocanal de $0,4 \mu \mathrm{m}, \mathrm{a} \Delta \mathrm{P}_{\mathrm{tm}}=300 \mathrm{kPa}$ $\mathrm{u}=3,7 \mathrm{~m} / \mathrm{s}$ e $\mathrm{T}=25^{\circ} \mathrm{C}$. (a) Xantana $1000 \mathrm{ppm}$;

(b) Guar 1000 ppm; (c) Xantana 900 ppm/Guar 100 ppm;

(d) Xantana 100 ppm/Guar 900 ppm;

(e) Xantana $750 \mathrm{ppm} / \mathrm{Guar} 250 \mathrm{ppm}$;

(f) Xantana $250 \mathrm{ppm} / \mathrm{Guar} 750 \mathrm{ppm}$;

(g) Xantana 500 ppm/Guar 500 ppm 84

FIGURA 4.29 - Resultados da análise do permeado pela técnica de infravermelho, na forma normalizada para experimentos realizados com membranas monocanal de $0,4 \mu \mathrm{m}$, a $\Delta \mathrm{P}_{\mathrm{tm}}=300 \mathrm{kPa}, \mathrm{u}=3,7 \mathrm{~m} / \mathrm{s} \mathrm{e} \mathrm{T}=25^{\circ} \mathrm{C}$.

(a) Xantana 1000 ppm; (b) Guar 1000 ppm. 85

FIGURA D.1 - Porosimetria de mercúrio. Gráfico da taxa de variação do volume específico em função do diâmetro:

(a) (C1T+); (b) (C1T-); (c) (C2T+); (d) (C3T-);

(e) (C2T-); (f) (C4T+) 119 


\section{LISTA DE TABELAS}

TABELA 2.1 - Porcentagem dos componentes da goma Guar comercial .................. 28

TABELA 3.1 - Região de absorção em diferentes tipos de ligações .......................... 59

TABELA 4.1 - Medidas de Carbono Orgânico Total de gomas

Xantana e Guar a $25^{\circ} \mathrm{C}$ na membrana comercial

monocanal com tamanho de poro de $0,2 \mu \mathrm{m}$.

TABELA 4.2 - Medidas de Carbono Orgânico Total de gomas Xantana

e Guar a $25^{\circ} \mathrm{C}$ no tubo microporoso $(\mathrm{C} 1 \mathrm{~T}+)$.

TABELA 4.3 - Medidas de Carbono Orgânico Total de gomas Xantana

e Guar a $40^{\circ} \mathrm{C}$ no tubo microporoso $(\mathrm{C} 1 \mathrm{~T}+)$.

TABELA 4.4 - Medidas de Carbono Orgânico Total de gomas Xantana

e Guar a $40^{\circ} \mathrm{C}$ na membrana comercial multicanal com tamanho de poro de $0,2 \mu \mathrm{m}$

TABELA A.1 -Vazão transmembrana para soluções puras e proporcionais de goma Xantana e Guar, à temperaturas de $25^{\circ} \mathrm{C}$, pressão de $300 \mathrm{kPa}$ e velocidade de escoamento de $3,7 \mathrm{~m} . \mathrm{s}^{-1}$, para a membrana multicanal com tamanho nominal de poro de $0,2 \mu \mathrm{m}$ 97

TABELA A.2 -Vazão transmembrana para soluções puras e proporcionais de goma Xantana e Guar, à temperaturas de $40^{\circ} \mathrm{C}$, pressão de $300 \mathrm{kPa}$ e velocidade de escoamento de $3,7 \mathrm{~m} . \mathrm{s}^{-1}$, para a membrana multicanal com tamanho nominal de poro de $0,2 \mu \mathrm{m}$ 98

TABELA A.3 -Vazão transmembrana para soluções puras e proporcionais de goma Xantana e Guar, à temperaturas de $25^{\circ} \mathrm{C}$, pressão de $300 \mathrm{kPa}$ e velocidade de escoamento de $3,7 \mathrm{~m} \cdot \mathrm{s}^{-1}$, para tubo microporoso $\mathrm{C} 1 \mathrm{~T}+$ com tamanho nominal de poro de $0,3 \mu \mathrm{m}$ 98 
TABELA A.4 -Vazão transmembrana para soluções puras e proporcionais de goma Xantana e Guar, à temperaturas de $40^{\circ} \mathrm{C}$, pressão de $300 \mathrm{kPa}$ e velocidade de escoamento de $3,7 \mathrm{~m} . \mathrm{s}^{-1}$, para tubo microporoso $\mathrm{C} 1 \mathrm{~T}+$ com tamanho nominal de poro de $0,3 \mu \mathrm{m}$ 99

TABELA A.5 -Vazão transmembrana para soluções puras e proporcionais de goma Xantana e Guar, à temperaturas de $25^{\circ} \mathrm{C}$, pressão de $300 \mathrm{kPa}$ e velocidade de escoamento de $3,7 \mathrm{~m} \cdot \mathrm{s}^{-1}$, para membrana monocanal com tamanho nominal de poro de $0,2 \mu \mathrm{m}$ 99

TABELA A.6 -Vazão transmembrana para soluções puras e proporcionais de goma Xantana e Guar, à temperaturas de $40^{\circ} \mathrm{C}$, pressão de $300 \mathrm{kPa}$ e velocidade de escoamento de $3,7 \mathrm{~m} . \mathrm{s}^{-1}$, para membrana monocanal com tamanho nominal de poro de $0,2 \mu \mathrm{m}$ 100

TABELA A.7 -Vazão transmembrana para soluções puras e proporcionais de goma Xantana e Guar, à temperaturas de $25^{\circ} \mathrm{C}$, pressão de $300 \mathrm{kPa}$ e velocidade de escoamento de $3,7 \mathrm{~m} . \mathrm{s}^{-1}$, para membrana monocanal com tamanho nominal de poro de $0,4 \mu \mathrm{m}$

TABELA A.8 -Vazão transmembrana para soluções puras e proporcionais de goma Xantana e Guar, à temperaturas de $40^{\circ} \mathrm{C}$, pressão de $300 \mathrm{kPa}$ e velocidade de escoamento de $3,7 \mathrm{~m} . \mathrm{s}^{-1}$, para membrana monocanal com tamanho nominal de poro de $0,4 \mu \mathrm{m}$

TABELA A.9 -Vazão transmembrana para soluções puras e proporcionais de goma Xantana e Guar, à temperaturas de $25^{\circ} \mathrm{C}$, pressão de 300,400 e $500 \mathrm{kPa}$ e velocidade de escoamento de 2,6 m.s ${ }^{-1}$, para membrana monocanal com tamanho nominal de poro de $0,4 \mu \mathrm{m}$ 
TABELA A.10 -Vazão transmembrana para soluções puras e proporcionais de goma Xantana e Guar, à temperaturas de $25^{\circ} \mathrm{C}$, pressão de 300,400 e $500 \mathrm{kPa}$ e velocidade de escoamento de $3,7 \mathrm{~m} . \mathrm{s}^{-1}$, para membrana monocanal com tamanho nominal de poro de $0,4 \mu \mathrm{m}$ 103

TABELA A.11 -Vazão transmembrana para soluções puras e proporcionais de goma Xantana e Guar, à temperaturas de $25^{\circ} \mathrm{C}$, pressão de 300, 400 e $500 \mathrm{kPa}$ e velocidade de escoamento de $4,7 \mathrm{~m} . \mathrm{s}^{-1}$, para membrana monocanal com tamanho nominal de poro de $0,4 \mu \mathrm{m}$ 104

TABELA A.12 -Vazão transmembrana para soluções puras e proporcionais de goma Xantana e Guar, à temperaturas de $25^{\circ} \mathrm{C}$, pressão de 300,400 e $500 \mathrm{kPa}$ e velocidade de escoamento de $5,7 \mathrm{~m} . \mathrm{s}^{-1}$, para membrana monocanal com tamanho nominal de poro de $0,4 \mu \mathrm{m}$

TABELA A.13 -Vazão transmembrana para solução de Xantana (1.000ppm), à temperatura de $25^{\circ} \mathrm{C}$, velocidade de $1,5 \mathrm{~m} . \mathrm{s}^{-1}$ e pressão de $300 \mathrm{kPa}$, para tubos microporosos (C1T-, C2T-, C2T+e C3T-) 106

TABELA A.14 -Vazão transmembrana para solução de Xantana (1.000ppm), à temperatura de $25^{\circ} \mathrm{C}$, velocidade de $3,3 \mathrm{~m} . \mathrm{s}^{-1}$ e pressões de 400 e $500 \mathrm{kPa}$, para tubos microporosos (C1T-, C2T-, C2T+e C3T-) 107

TABELA B.1 - Propriedades reológicas das soluções puras e proporcionais de goma Xantana e Guar, à temperaturas de 25 e $40^{\circ} \mathrm{C}$, pressão de $300 \mathrm{kPa}$ e velocidade de escoamento de $3,7 \mathrm{~m} \cdot \mathrm{s}^{-1}$, para a membrana multicanal com tamanho nominal de poro de $0,2 \mu \mathrm{m}$ 109

TABELA B.2 - Propriedades reológicas das soluções puras e proporcionais de goma Xantana e Guar, à temperaturas de 25 e $40^{\circ} \mathrm{C}$, pressão de $300 \mathrm{kPa}$ e velocidade de escoamento de $3,3 \mathrm{~m} \cdot \mathrm{s}^{-1}$, para o tubo microporoso $\mathrm{C} 1 \mathrm{~T}+$ com tamanho nominal de poro de $0,3 \mu \mathrm{m}$ 
TABELA B.3 -Propriedades reológicas das soluções puras e proporcionais de goma Xantana e Guar, à temperaturas de 25 e $40^{\circ} \mathrm{C}$, pressão de $300 \mathrm{kPa}$ e velocidade de escoamento de $3,7 \mathrm{~m} \cdot \mathrm{s}^{-1}$, para a membrana monocanal com tamanho nominal de poro de $0,2 \mu \mathrm{m}$ 110

TABELA B.4 -Propriedades reológicas das soluções puras e proporcionais de goma Xantana e Guar, à temperaturas de 25 e $40^{\circ} \mathrm{C}$, pressão de $300 \mathrm{kPa}$ e velocidade de escoamento de $3,7 \mathrm{~m} . \mathrm{s}^{-1}$, para a membrana monocanal com tamanho nominal de poro de $0,4 \mu \mathrm{m}$

TABELA B.5 -Propriedades reológicas das soluções puras e proporcionais de goma Xantana e Guar, à temperatura de $25^{\circ} \mathrm{C}$, velocidades de 2,$6 ; 3,7 ; 4,7$ e 5,7 m.s ${ }^{-1}$ e pressão de $300 \mathrm{kPa}$, para a membrana monocanal com tamanho nominal de poro de $0,4 \mu \mathrm{m}$

TABELA B.6 -Propriedades reológicas das soluções puras e proporcionais de goma Xantana e Guar, à temperatura de $25^{\circ} \mathrm{C}$, velocidades de 2,$6 ; 3,7 ; 4,7$ e $5,7 \mathrm{~m} \cdot \mathrm{s}^{-1} \mathrm{e}$ pressão de $400 \mathrm{kPa}$, para a membrana monocanal com tamanho nominal de poro de $0,4 \mu \mathrm{m}$

TABELA B.7 -Propriedades reológicas das soluções puras e proporcionais de goma Xantana e Guar, à temperatura de $25^{\circ} \mathrm{C}$, velocidades de 2,$6 ; 3,7 ; 4,7$ e $5,7 \mathrm{~m} \cdot \mathrm{s}^{-1} \mathrm{e}$ pressão de $500 \mathrm{kPa}$, para a membrana monocanal com tamanho nominal de poro de $0,4 \mu \mathrm{m}$.

TABELA B.8 - Propriedades reológicas da solução de Xantana (1.000ppm), à temperatura de $25^{\circ} \mathrm{C}$, velocidades de 1,5 e $3,3 \mathrm{~m} \cdot \mathrm{s}^{-1}$ e pressões de 300, 400 e $500 \mathrm{kPa}$, para tubos microporosos (C1T-, C2T-, C2T+e C3T-) 
TABELA C.1 - Análise de absorbância (A) e comprimento de onda $(\lambda)$ para soluções puras de goma Xantana à temperatura de $25^{\circ} \mathrm{C}$, em diferentes tubos microporosos com tamanho nominal de poro predominantemente de $0,3 \mu \mathrm{m}$ 114

TABELA C.2 - Análise de absorbância (A) e comprimento de onda $(\lambda)$ para soluções puras e proporcionais de goma Xantana e Guar a $25^{\circ} \mathrm{C}$ e $40^{\circ} \mathrm{C}$, da membrana comercial importada com tamanho nominal de poro de $0,4 \mu \mathrm{m}$

TABELA C.3 - Análise de absorbância (A) e comprimento de onda $(\lambda)$ para soluções puras e proporcionais de goma Xantana e Guar a $40^{\circ} \mathrm{C}$, da membrana comercial importada com tamanho nominal de poro de $0,2 \mu \mathrm{m}$

TABELA C.4 - Análise de absorbância (A) e comprimento de onda $(\lambda)$ para soluções puras e proporcionais de goma Xantana e Guar a $25^{\circ} \mathrm{C}$, da membrana comercial importada com tamanho nominal de poro de $0,4 \mu \mathrm{m}$, em diferentes temperaturas e pressões 


\section{LISTA DE SÍMBOLOS}

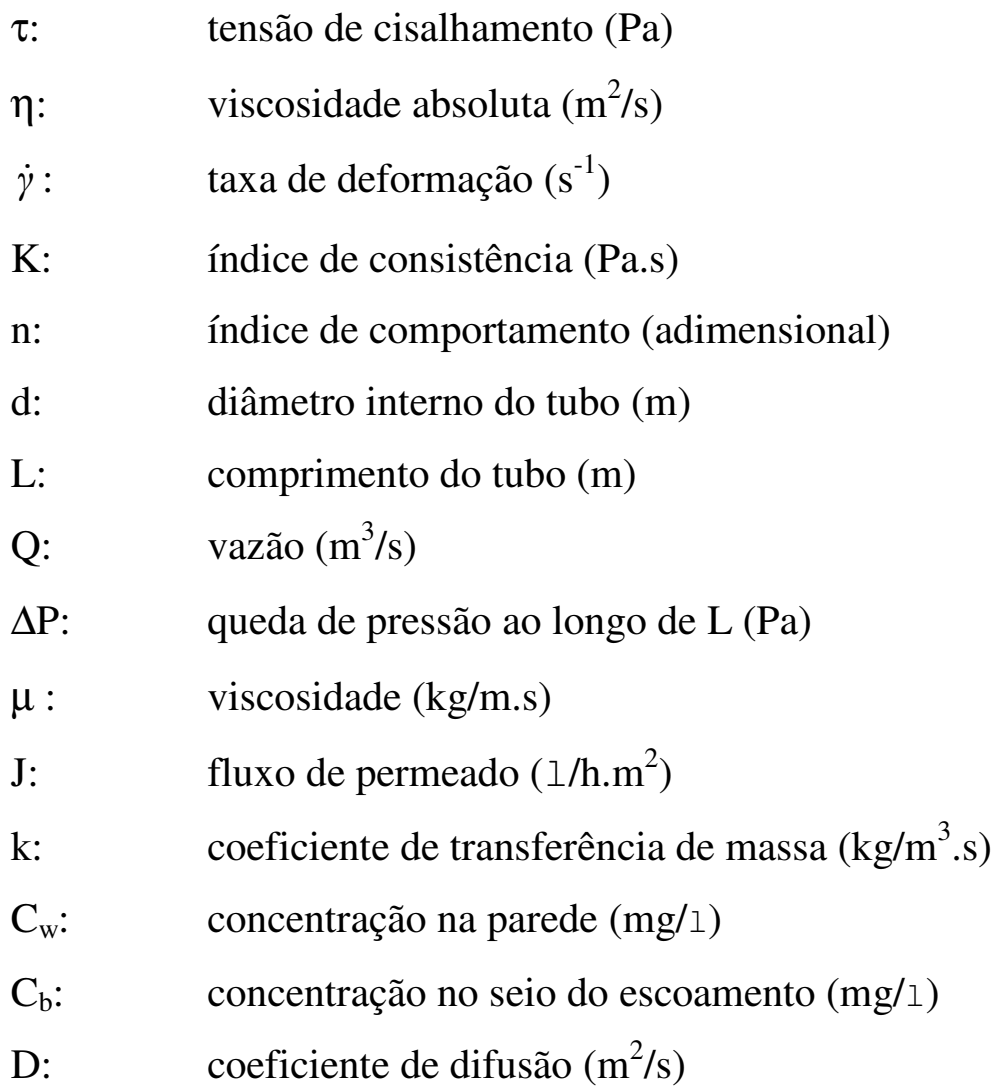

$\mathrm{n}_{\mathrm{b}}$, e $\mathrm{n}_{\mathrm{w}}$ : índice de comportamento do fluido e da parede, respectivamente (adimensional)

$\mathrm{K}_{\mathrm{b}}$, e $\mathrm{K}_{\mathrm{w}}$ : índice de consistência do fluido e parede, respectivamente (Pa.s)

B expoente para a taxa de deformação na parede ou termo da velocidade axial

$\mu_{\mathrm{PN}}: \quad$ viscosidade equivalente ao processo Newtoniano

$\mu_{\mathrm{a}}: \quad$ viscosidade aparente

$\tau_{\mathrm{w}}$ e $\dot{\gamma}_{w}$ : tensão de cisalhamento $(\mathrm{Pa})$ e a taxa de deformação $\left(\mathrm{s}^{-1}\right)$ na parede da membrana

u: $\quad$ velocidade $(\mathrm{m} / \mathrm{s})$

$v \quad$ velocidade tangencial $(\mathrm{m} / \mathrm{s})$

$\mathrm{N}$ : $\quad$ número de tubos ou canais

Re’ número de Reynolds generalizado (adimensional)

$\rho: \quad$ densidade do fluido $(\mathrm{kg} / \mathrm{l})$

$\dot{\gamma}_{w}: \quad$ taxa de deformação na parede $\left(\mathrm{s}^{-1}\right)$

$\mathrm{n}_{\mathrm{bl}}$ : índice de comportamento na camada limite (adimensional) 


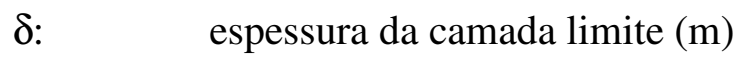

$\mathrm{C}_{\mathrm{P}}$ : $\quad$ concentração do componente a ser separado no líquido permeável (mg/l)

$\mathrm{C}_{\mathrm{F}}$ : concentração na alimentação $(\mathrm{mg} / \mathrm{l})$

$\mathrm{C}_{\mathrm{M}}$ : $\quad$ concentração na superfície da membrana $(\mathrm{mg} / \mathrm{l})$

I: $\quad$ concentração de polarização (adimensional)

$\mathrm{r}_{\text {in }}$ : rejeição do soluto (adimensional)

$\mathrm{Pe}_{\mathrm{M}}$ : número de Peclet (adimensional)

$\Pi$ : $\quad$ fluxo (adimensional)

$\mathrm{J}_{0}$ : $\quad$ fluxo de permeado inicial $\left(\mathrm{I} / \mathrm{hm}^{2}\right)$

$\Delta \mathrm{P}_{\mathrm{tm}}: \quad$ pressão transmembrana $(\mathrm{Pa})$

$\mathrm{R}: \quad$ raio do tubo $(\mathrm{m})$

Sh: número de Sherwood (adimensional)

$\mathrm{F}_{\mathrm{si}}$ : $\quad$ fração de água na solução inicial ( 1 )

Fsf: $\quad$ fração de água na solução filtrada (1) 
SUMÁRIO

1. Introducão

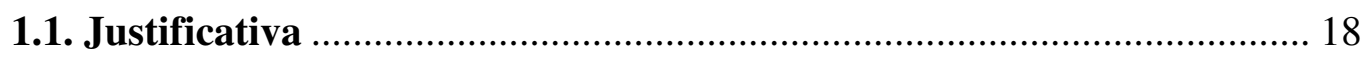



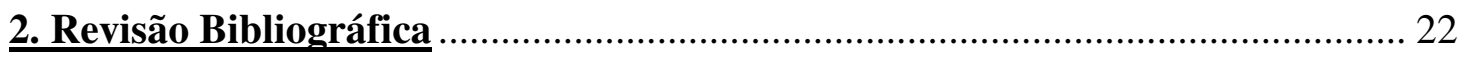

2.1. Polissacarídeos Bacterianos ................................................................... 22

2.2. Polissacarídeos de Origem Vegetal ......................................................... 24

2.3. Produção de Polissacarídeos em Escala Comercial .................................. 26

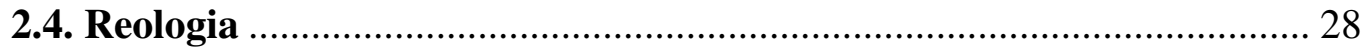

2.4.1. Medidas Reológicas de Fluidos...................................................... 33

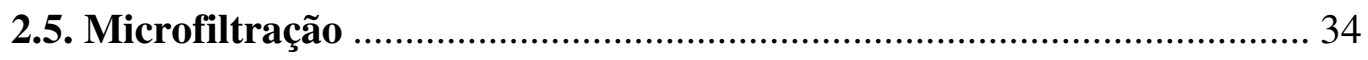

2.5.1. Conceituação e Fenomenologia ....................................................... 34

2.5.2. Microfiltração Tangencial .............................................................. 36

2.5.3. Membrana

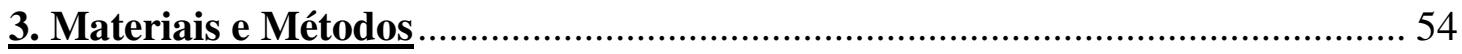

3.1. Agentes da Microfiltração …………………………………………...... 54

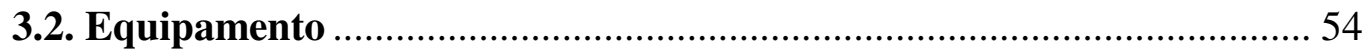

3.3. Propriedades Físicas ................................................................................ 57

3.3.1. Comportamento Reológico ……………………………………....... 57

3.3.2. Espectrometria no Infravermelho.................................................... 58

3.4. Limpeza do Equipamento …………………………........................... 59

4. Resultados e Discussão

5. Conclusão

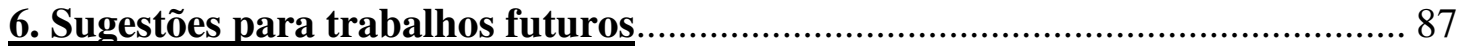

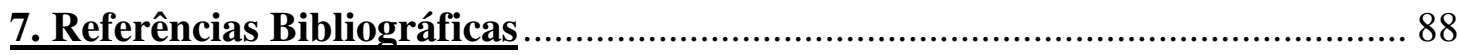

Anexo A

Anexo B

Anexo C

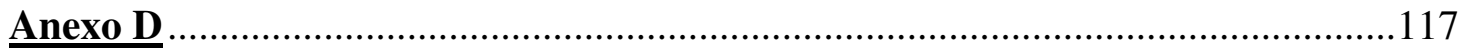




\section{Introducão}

\subsection{Justificativa}

Um dos processos cada vez mais utilizados, na indústria química é o denominado de microfiltração. A microfiltração é um processo que separa partículas com diâmetros entre 0,1 e $10 \mu \mathrm{m}$ em suspensão, passando a fase líquida através dos poros de uma membrana. Este procedimento têm sido utilizado em indústrias de alimentos, cosméticos, farmacêutica, no tratamento de efluentes e em biotecnologia, por exemplo, para separar células do caldo de fermentação para a obtenção de um filtrado clarificado ou esterilizado (SCOTT, 1995).

A maior vantagem técnica deste tipo de filtração é a boa adaptação a materiais sensíveis a temperatura e a não influência de compostos químicos como os processos de destilação e precipitação. A filtração por membrana oferece simplicidade e baixo custo de operação em comparação com a separação por centrifugação, filtração a vácuo e secagem por vaporização (spray drying). Na produção de sucos e açúcares, em seu processo de concentração, utiliza-se a microfiltração, sendo vantajosa do ponto de vista econômico, com menor consumo de energia em relação ao equipamento tradicional de evaporação.

Uma outra vantagem da tecnologia com membrana, quando comparada ao processo convencional de extração de água, é a ausência de mudança de fase ou estado do solvente durante o processo. Evaporação e congelamento são duas técnicas comuns de retirada de água usadas para produtos líquidos. Como o processo com membrana não requer esta mudança de fase, torna-o mais viável em termos de consumo de energia.

Neste tipo de processo, não há necessidade de um equipamento complicado de transferência de calor e a operação da membrana que requer apenas energia elétrica para funcionar a bomba, pode ser situada longe da planta de geração de energia primária. 
Não é necessário também um condensador, evitando problemas como poluição térmica e sobrecarga do sistema de tratamento de efluentes.

Os processos com membrana podem ser realizados a temperatura ambiente, até mesmo operar em temperaturas mais baixas, para prevenir o crescimento de microrganismos ou desnaturação de componentes sensíveis ao calor ou temperaturas mais altas para minimizar o desenvolvimento microbiológico, para diminuir a viscosidade do concentrado, o qual reduz o custo da bomba e melhora a transferência de massa. Assim os problemas com a degradação térmica e oxidativa comuns aos processos de evaporação podem ser evitados.

A moderna indústria alimentícia vem cada vez mais tornando-se dependente da produção de alimentos altamente processados, ao invés de simplesmente preservar as matérias-primas obtidas no campo. Muito desse desenvolvimento tem resultado da criatividade ou manipulação empírica, muitas vezes por tentativa e erro, de ingredientes sobre os quais têm-se pouco conhecimento científico. Entre estes, destaca-se uma classe de polissacarídeos denominados hidrocolóides, ou gomas, como são comumente conhecidos, cuja característica mais importante, sob o ponto de vista tecnológico, é sua capacidade de determinar ou modificar a estrutura de fluidos.

O desenvolvimento e otimização da biotecnologia nacional para obtenção de hidrocolóides são de grande importância econômica para o Brasil, uma vez que os insumos básicos para sua produção e purificação (açúcar e álcool) têm baixo custo relativo e grande disponibilidade no mercado, o que poderá tornar o produto competitivo e possibilitaria a substituição das importações.

Os hidrocolóides possuem uma grande variedade de estruturas químicas, peso molecular, composição, solubilidade e outras características que lhes conferem uma ampla gama de propriedades funcionais (BEMILLER, 1988). São utilizados como estabilizantes, espessantes, gelificantes, crio-protetores, sendo muitas vezes os principais responsáveis pela textura (corpo, viscosidade, consistência) dos alimentos processados (IGOE, 1982; SOUZA, 1984). Segundo Patton e Lindblom (1962), são também utilizados em produtos de limpeza industrial e suas excelentes propriedades de suspensão das soluções são muito aplicados em sprays para agricultura, emulsões de látex, fundição de produtos químicos, lubrificantes e outros produtos contendo líquidos insolúveis, sólidos e polímeros. A larga tolerância à temperatura, a reologia e a estabilidade em soluções de sais, permitem várias aplicações na indústria de petróleo e 
de explosivos. Em função da compatibilidade de polímeros, são muito utilizados como corantes em formulações para impressão e soluções para aplicações em indústria têxtil. (SANDVICK e MAERKER, 1977).

O uso de hidrocolóides na indústria de alimentos baseia-se principalmente no aproveitamento de suas propriedades funcionais, que estão relacionadas à capacidade de manter partículas em suspensão e de reter água (GLICKSMAN, 1982). Alguns hidrocolóides provocam uma imobilização extrema da água, fazendo com que o sistema adote características de um sólido capaz de reter sua forma, convertendo-se em um gel (SZCZCESNIAK, 1986).

O maior problema em relação à utilização de hidrocolóides extraídos de fontes naturais é a escassez e a possibilidade de esgotamento das mesmas. Com o avanço da tecnologia, a utilização desses hidrocolóides tem aumentado rapidamente e com isso suas fontes naturais são cada vez mais exploradas, verificando-se a necessidade de procurar fontes alternativas de produção, de forma a racionalizar seu uso. Nesse sentido, as bactérias representam uma ótima fonte produtora alternativa.

O termo hidrocolóides refere-se a uma ampla variedade de compostos onde podem ser incluídos polissacarídeos de origem vegetal, marinha ou microbiana. As gomas de origem vegetal são obtidas de exsudados de árvores (gomas Arábica e Karaya), de sementes (gomas Guar e Locusta) e de frutas cítricas (Pectina), enquanto as de origem marinha são retiradas de algas (Alginato, Ágar, Carragena). Entre as de origem microbiana encontram-se a Dextrana, Xantana, Curdlana e Gelana.

Misturas de gomas são utilizadas com a finalidade de obter propriedades funcionais adequadas e reduzir os custos. Por este motivo, uma análise cuidadosa da interação sinergética polissacarídeo-polissacarídeo é relevante para melhor entender seu comportamento em diferentes processos, em seu manuseio e armazenamento (MA e BARBOSA-CÁNOVAS, 1993). 


\subsection{Objetivos}

O objetivo geral desta dissertação é a investigação experimental do processo de filtração tangencial aplicado à concentração de soluções macromoleculares utilizando-se de diferentes meios filtrantes (membranas e tubos microporosos). Os seguintes objetivos específicos acerca do processo são:

- Estudar o comportamento da filtração tangencial de suspensões aquosas produzidas em diferentes concentrações com gomas Guar e Xantana nas temperaturas de $25{ }^{\circ} \mathrm{C}$ e $40{ }^{\circ} \mathrm{C}$;

- Investigar características da sinergia das misturas através do seu comportamento reológico;

- Estudar aspectos da fluidodinâmica e da transferência de massa de filtração tangencial com meios filtrantes do tipo membrana e tubo microporoso. 


\section{Revisão Bibliográfica}

\subsection{Polissacarídeos Bacterianos}

Os polissacarídeos de origem microbiana, chamados biopolímeros, apresentam algumas vantagens de sua obtenção em relação às outras gomas, tais como: produção independente de condições climáticas, possibilidade de utilização de matérias-primas regionais, maior rapidez na obtenção do produto acabado e necessidade de espaço relativamente pequeno. Além disso, as gomas de origem microbiana apresentam maior uniformidade em suas propriedades físico-químicas devido à especificidade do microrganismo utilizado e à possibilidade de um rígido controle dos parâmetros de fermentação, como $\mathrm{pH}$, temperatura, taxa de aeração, velocidade de agitação, tempo de fermentação e composição do meio de cultura.

Entre os biopolímeros mais utilizados, a goma Xantana é, sem dúvida, a mais importante, representando $90 \%$ do volume total de vendas. O maior fornecedor desse polímero é a Kelco Co. situada nos EUA. Entretanto a concorrência torna-se cada dia mais severa, com o aparecimento de novas indústrias produtoras no mercado.

A goma Xantana é produzida pela fermentação de um carboidrato pelo microrganismo Xanthomonas campestris. É um heteropolissacarídeo extracelular solúvel em água, de alto peso molecular, com propriedades funcionais únicas, tais como tolerância em alimentos ácidos e salgados, estabilização em baixas concentrações, alta estabilidade ao congelamento-descongelamento e são altamente desejáveis em produto de formulação complexa (SANDERSON, 1981). 
A unidade de repetição da estrutura da goma Xantana é mostrada na Figura 2.1. Sua cadeia principal é constituída de unidades de $\beta$-D-glicose ligadas nas posições 1 e 4, sua estrutura química é idêntica a da celulose. A cadeia de trissacarídeos contêm uma unidade de D-ácido Glucônico entre duas unidades de D-manose ligadas nas posições 0 e 3 de glicose na cadeia principal. Aproximadamente na metade da D-manose terminal contém uma molécula de ácido pirúvico ligado pelas posições 4 e 6, com uma distribuição desconhecida. A unidade D-manose está ligada a cadeia principal e contêm um grupo acetil nas posições 0 e 6 . A presença dos ácidos acéticos e pirúvicos produzem um tipo de polissacarídeo aniônico (KOVACS e KANG, 1997).

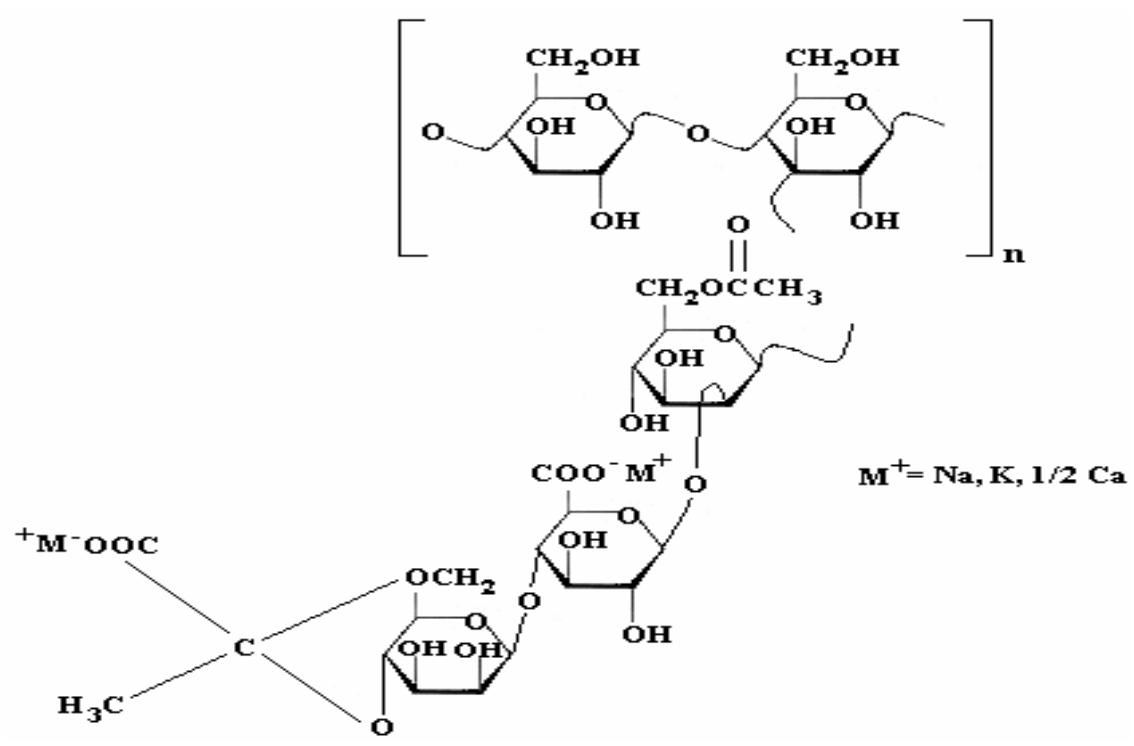

Figura 2.1: Estrutura do polissacarídeo extracelular da X. campestris

A ramificação do trissacarídeo está alinhada com a espinha do polímero. $\mathrm{O}$ resultado da cadeia rígida pode existir como uma hélice simples, dupla ou tripla, na qual interage com outras moléculas de polímero para formar um complexo. A distribuição do peso molecular depende da associação entre cadeias, que são formadas por agregação de diversas cadeias individuais.

Um aspecto de extrema importância em relação aos hidrocolóides de origem microbiana é a necessidade de um rígido controle das condições de fermentação, uma vez que diferentes parâmetros de produção levam à obtenção de produtos de características distintas, por exemplo o peso molecular, que varia em torno de $2,4 \times 10^{7}$.

Soluções de Xantana obtidas por dissolução a temperaturas moderadas tendem a ser altamente viscosas. A temperatura da dissolução afeta positivamente a viscosidade controlando a conformação molecular e a aparência das estruturas ordenadas. A 
molécula da Xantana tem duas conformações, hélice e espiral. Uma propriedade importante das soluções de Xantana é a interação com plantas galactomananas, tais como goma Locusta e goma Guar. A adição de qualquer uma destas galactomananas na suspensão aquosa de Xantana em temperatura ambiente causa um aumento sinergético na viscosidade (KOVACS e KANG, 1997).

A grande aceitação da goma Xantana pelas indústrias alimentícias ocorreu por essa ter sido a primeira goma de origem microbiana aprovada para uso em alimentos pelo FDA (Food and Drug Administration), em 1969. Somente em 1992 um segundo biopolímero, a goma gelana também produzida pela Kelco Co., obteve aprovação pelo mesmo órgão, tornando-se uma alternativa para o mercado (PSZCZOLA, 1993). Devese ter em mente, no entanto, que existe um enorme potencial para a descoberta e desenvolvimento de novos biopolímeros produzidos a partir de microorganismos dispersos na natureza. O Brasil em particular, devido a sua enorme biodiversidade, pode ser uma fonte importante de bactérias e fungos produtores de polissacarídeos ainda desconhecidos, que poderiam ser isolados a partir de amostras de solo e plantas nativas.

A goma Xantana possui propriedades e características tais como: alta viscosidade, mesmo em baixas concentrações; estabilidade em relação ao calor, resistindo a altas temperaturas durante o processamento; excelente solubilidade e estabilidade em meio ácido; estabilidade na presença de sais, principalmente cloreto de sódio; viscosidade alta em repouso e baixa sob cisalhamento, como resultado de interações moleculares fracas; eficiente como estabilizador de emulsões, evitando a separação da gordura nos sistemas óleo/água; é de natureza altamente pseudoplástica, diminuindo o arraste durante o escoamento; nos embutidos de carnes retém a umidade e evita a exsudação da gordura, também chamado de "encapsulamento branco" (SANDERSON, 1981).

\subsection{Polissacarídeos de Origem Vegetal}

Segundo Kovacs e Kang (1997) a goma Guar é extraída da semente da planta leguminosa Cyamopsis tetragonoloba. Esta planta tem crescido na Índia e no Paquistão por séculos, onde é uma das mais importantes espécies cultivadas, usada como alimento tanto para humanos quanto para animais. Esta planta é bem conhecida na Ásia e foi introduzida nos Estados Unidos após 1903 quando foi avaliada como uma possível 
espécie cultivada no Texas, Arizona e Califórnia pelo departamento de agricultura deste país.

A goma Guar é um polissacarídeo não iônico, de alto peso molecular, que varia entre $2 \times 10^{5}$ a $3 \times 10^{5}$ e sua estrutura é mostrada na Figura 2.2. Consiste de $\beta(1 \rightarrow 6)$ ligado a manoses com a ramificação $\beta(1 \rightarrow 4)$ ligado a unidades de galactose. A razão entre manose e galactose é de 2:1 (KOVACS e KANG, 1997).

Este hidrocolóide é estável no intervalo de $\mathrm{pH}$ de 1 a 10, é solúvel em água fria e possui alta viscosidade na presença de cátions (GLICKSMAN, 1969).

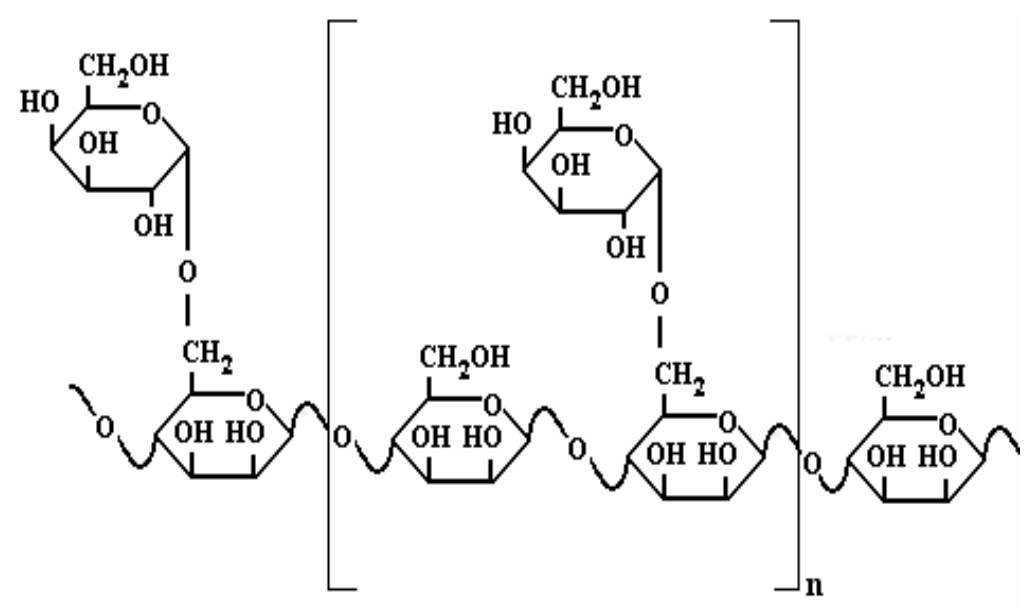

Figura 2.2: Estrutura molecular da goma Guar

A goma Guar, assim como a Xantana é amplamente aplicada nas indústrias como agentes espessante e estabilizante.

Esta goma pode ser facilmente despolimerizada, por hidrólise química. Esta hidrólise ocorre a baixos valores de $\mathrm{pH}$ e altas temperaturas e pode ser usada para preparar uma série de gomas Guar com peso molecular variado (TUINIERA, GROTENHUISA e KRUIF, 2000).

Polissacarídeos similares a goma Guar são facilmente hidrolisados em monossacarídeos em condições extremamente ácidas, por exemplo quando misturados com ácido sulfúrico a 12 M. Entretanto, sob condições mais amenas, podem também permanecerem inseparáveis ou serem parcialmente hidrolisados para produzir uma mistura variável de monossacarídeos, oligossacarídeos e polissacarídeos com uma ordem extensa de grau de polimerização.

Exceto às condições físico-químicas usuais, tais como temperatura, $\mathrm{pH} \mathrm{e}$ concentração, a taxa de degradação dos polissacarídeos é também influenciada pela conformação das moléculas (HJERDE et al., 1994). 


\subsection{Produção de Polissacarídeos em Escala Comercial}

A produção industrial do biopolímero por fermentação é realizada em um equipamento fechado para promover agitação, esterilização e aeração. O carboidrato usado como substrato pode ser um açúcar ou material com alto teor de açúcar. Os substratos mais usado são o xarope de milho, beterraba ou melaço de cana, dextrose, ou sacarose e são selecionados de acordo com o custo. O nitrogênio necessário para o crescimento da cultura pode ser colocado pela adição de qualquer fonte de nitrogênio convencional, cuidando que, pelo menos uma parte deste seja de um composto orgânico (GODET, 1973).

Outros elementos inorgânicos são necessários em todas as fermentações na forma de sais. Exemplos destes podem ser o fósforo, na forma de fosfato de amônio, sódio ou potássio; enxofre como sulfato de potássio ou sódio e magnésio como sulfato de magnésio.

No processo de fermentação em escala comercial normalmente são seguidas quatro etapas. Inicia-se com um crescimento prévio das bactérias em frascos de um litro, os quais são usados como inóculo do meio de cultura. O volume utilizado como inóculo em escala comercial é aproximadamente $1 \%$ do volume do fermentador. A temperatura de fermentação é em torno de $28^{\circ} \mathrm{C}$ e o tempo pode ser entre 60 e 70 horas. As concentrações da fonte de carbono que fornecem melhor rendimento do polissacarídeo encontram-se entre $1 \%$ a $5 \%$ de glicose (LILLY, WILSON e LEACH, 1958). Altas concentrações da fonte de carbono promovem uma redução na eficiência da conversão desta em polissacarídeo (KOVACS e KANG, 1997). Também foi observado que a glicose, a sacarose e o amido foram os mais eficientes na produção de polissacarídeos. Um fator limitante do estágio de fermentação é a alta viscosidade do caldo. Por causa desta viscosidade, é difícil ocorrer uma boa difusão de oxigênio nas últimas horas da fermentação. Portanto, a quantidade máxima de açúcar reduzida usada na fermentação é determinada pela viscosidade final do meio e medida pela difusão do oxigênio. No final da fermentação, o caldo é esterilizado por vapor para destruir todos os microrganismos viáveis. Esta esterilização é fácil devido a sensibilidade ao calor da Xanthomonas campestris.

No processo comercial, com a manutenção de ótimas condições para produção do polissacarídeo, incluindo um alto grau de aeração e temperatura constante, o processo de fermentação é muito mais rápido e o pH da mistura decresce gradualmente. 
Depois de parte substancial de substrato (carboidrato) ser consumido, o pH é mantido pela adição de base para fornecer íons metálicos para uma maior produção da goma. $\mathrm{O}$ controle do $\mathrm{pH}$ próximo da neutralidade permite que a síntese da goma continue até que todo o carboidrato seja consumido, até a completa fermentação (KOVACS e KANG, 1997).

A recuperação do biopolímero do caldo fermentado é difícil, por causa da notável estabilidade deste na solução. Entretanto, um método que pode ser utilizado consiste em concentrar por evaporação a água deste caldo. Este método é tecnicamente factível e economicamente aceitável, mas tem a desvantagem de produzir um produto de baixa qualidade devido aos sais inorgânicos e os resíduos dos produtos orgânicos no qual foram adicionados na fermentação.

O método mais usado consiste na precipitação do polissacarídeo pela adição de álcool no caldo de fermentação. Qualquer álcool solúvel em água (do etanol até o tbutanol) pode ser usado. A goma precipitada é removida por equipamentos convencionais como filtros ou centrífugas. Os sólidos obtidos na separação são lavados com solvente e separados novamente no mesmo tipo de equipamento e secos em ar quente. O solvente residual separado durante a precipitação e nos estágios de lavagem é reciclado, depois concentrado novamente e purificado numa coluna de destilação para ser re-utilizado na próxima fermentação. A água da coluna que contém a maior parte dos resíduos (orgânicos e inorgânicos) da fermentação pode também ser reciclada, uma vez que, a DQO (demanda química de oxigênio) e a DBO (demanda bioquímica de oxigênio) variam ligeiramente dependendo dos materiais crus utilizados (fonte de carboidrato, fonte de oxigênio) e do rendimento da fermentação.

A biossíntese da goma Xantana pode ser geneticamente controlada tanto na estrutura química, quanto no peso molecular. Por esta razão podem ser produzidas gomas que tenham propriedades físicas e químicas uniformes. A goma Xantana, de acordo com as especificações do Food Chemicals Codex (National Research Council, 1972), foi designada com o nome Keltrol e aprovada como aditivo de alimentos pela Federal Food and Drug Administration, neste último caso a manufatura básica não é muito diferente; entretanto a seleção do material cru e o controle das operações envolvidas é cuidadoso para produzir a alta qualidade desejada.

Atualmente a variedade, estabilidade e o alto rendimento dos processos de fermentação que utilizam bactérias permitem produzir polissacarídeos em batelada ou em fermentação contínua fazendo-os um produto muito valioso. Entre os 
polissacarídeos microbianos de uso comercial se incluem as Gelanas, Dextranas, Welanas e Ramsanas.

A planta Guar é uma vagem, que fixa o nitrogênio no legume. As sementes da planta são compostas de casca (14-17\%), embrião (43-47\%) e endosperma (35-42\%). A produção da goma Guar, é feita pela trituração do endosperma depois de separado, o máximo possível, da casca e do embrião. Na prática, há usualmente um resíduo da casca e do embrião, devido a dificuldade encontrada para a separação completa durante o processo.

A casca pode ser removida pelo tratamento com ácido sulfúrico, aquecendo e triturando pelo tratamento de chamas ou pela trituração mecânica e peneiramento. Depois de remover a casca, trituração diferencial é usada para separar o embrião. O endosperma e o embrião podem ser separados desta maneira, devido a diferença da dureza de cada constituinte. O endosperma é estabelecido como uma partícula de tamanho fino e vendida como goma Guar.

Uma análise típica da goma Guar comercial é dada como se segue na Tabela 2.1:

Tabela 2.1: Porcentagem dos componentes da goma Guar comercial (Glicksman, 1969).

\begin{tabular}{|c|c|}
\hline Galactomananas & $78-82 \%$ \\
\hline Umidade & $10-13 \%$ \\
\hline Proteína & $4-5 \%$ \\
\hline Fibra Crua & $1,5-2,5 \%$ \\
\hline Cinzas & $0,5-0,9 \%$ \\
\hline Ferro & - \\
\hline Metais Pesados & 0 \\
\hline Arsênio & 0 \\
\hline Gordura & $0,5-0,75 \%$ \\
\hline
\end{tabular}

\subsection{Reologia}

Reologia é a ciência que estuda as relações entre a deformação e o fluxo de matéria. Inclui o estudo da deformação elástica e outros fenômenos não necessariamente associados ao fluxo. A matéria é deformada, ou começa a fluir, apenas quando uma tensão é aplicada. Esta deformação não pode ser recuperada, mesmo quando a tensão aplicada for cessada. A reologia depende da tensão, deformação, tempo e pode também incluir temperatura e outros parâmetros secundários. Os fluidos são, em geral, analisados por gráficos de taxa de deformação por tensão de cisalhamento, como ilustra a Figura 2.3. 
A classificação geral do comportamento reológico de diversos fluidos é mostrada na Figura 2.4 .
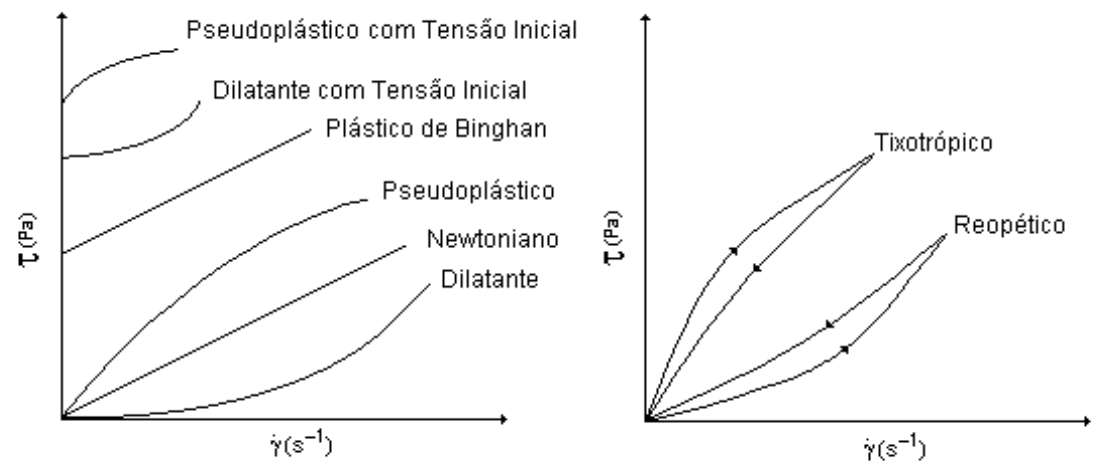

Figura 2.3: Reograma dos diversos tipos de fluidos

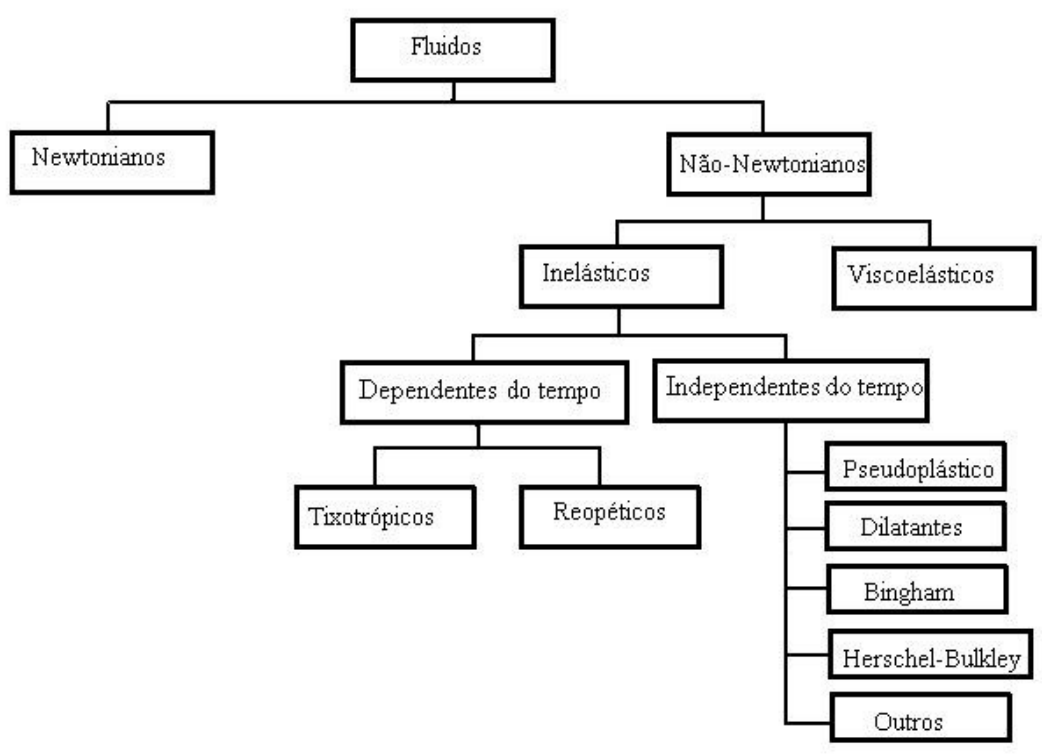

Figura 2.4: Classificação geral do comportamento reológico dos fluidos

A maneira mais comum de caracterizar um líquido ou um material fluido é observando sua viscosidade, que é a medida da resistência do fluido ao escoamento.

Dependendo do comportamento do fluido sob determinada força de cisalhamento, o material pode ser caracterizado como Newtoniano ou não Newtoniano. Os fluidos Newtonianos, pseudoplásticos, Bingham, Herschel-Bulkley e dilatantes, são independentes do tempo, já os sistemas tixotrópicos e reopéticos são dependentes do tempo (Fig. 2.3). 
Em sistemas Newtonianos, onde a tensão de cisalhamento é diretamente proporcional a taxa de deformação (Fig. 2.3), a viscosidade é constante e a medida de uma tensão é suficiente para caracterizar o sistema, sendo independente da taxa de deformação.

Entretanto a maioria dos fluidos alimentícios são não-Newtonianos, onde a viscosidade não é constante, mas é dependente da taxa de deformação.

O comportamento dos fluidos Newtonianos é mais frequente nos gases e líquidos ou soluções com baixo peso molecular e também para soluções de baixas concentrações de alguns polímeros de alto peso molecular.

A equação matemática que descreve seu comportamento é:

$$
\tau=\eta \dot{\gamma}
$$

onde $\tau$ é a tensão de cisalhamento (Pa), $\eta$ é a viscosidade absoluta (Pa.s) e $\dot{\gamma}$ é a taxa de deformação (1/s).

Fluidos não-Newtonianos são frequentemente encontrados em vários processos industriais, por exemplo, concentração por osmose reversa de sucos de frutas, ultrafiltração para produzir sucos de frutas clarificados diretamente do purê, microfiltração para separação de células e purificação da produção de polissacarídeos.

O comportamento não-Newtoniano pode ser encontrado em soluções de material polimérico de alto peso molecular, a não ser que sejam diluídos, suspensão de sólidos em líquidos, o qual se torna cada vez mais não-Newtoniano com o aumento da concentração de sólidos.

Em fluidos não-Newtonianos, os colóides são de maior importância e as propriedades relevantes que determinam seu comportamento reológico são: a forma da partícula, seu tamanho, sua flexibilidade e fácil deformação, sua solubilidade pela fase contínua, presença e magnitude de suas cargas elétricas.

O comportamento dos fluidos não Newtonianos ocorrem apenas quando as cadeias dos polímeros são longas o suficiente para emaranhar. A efetividade deste emaranhamento decresce com o aumento da taxa de deformação.

Os fluidos de Binghan são caracterizados por um linha reta em um gráfico de tensão de cisalhamento e taxa de deformação e mostra um decréscimo da viscosidade com um aumento da taxa de deformação depois do valor fornecido ser excedido (Fig. 2.3). Uma resistência inicial deve ser vencida por uma força mínima de cisalhamento no começo do fluxo. Uma vez que este valor fornecido é alcançado, o movimento começa e 
as substâncias agem no mesmo caminho que os fluidos Newtonianos. Exemplos de fluidos deste tipo, são as soluções ou suspensões concentradas de polímeros, como o amido e as proteínas.

Um fluido pseudoplástico escoa mais facilmente quando é agitado. É uma estrutura irreversível e mostra o decréscimo da viscosidade com o aumento da taxa de deformação.

A diminuição da viscosidade é resultado do alinhamento molecular que ocorre dentro de algumas substâncias. Este tipo de substância é chamada de "viscosidade estrutural”.

Um aumento na taxa de deformação orienta ou alinha as moléculas ocorrendo uma diminuição do atrito inicial resultando em uma viscosidade menor. Com uma taxa de deformação menor, as moléculas são apenas parcialmente alinhadas, proporcionando um aumento da viscosidade.

Medidas pseudoplásticas são reproduzidas e dependentes apenas da taxa de deformação e temperatura, que se diferencia das substâncias tixotrópicas, as quais são dependentes da taxa de deformação, temperatura e tempo. O tempo não influencia nas medidas das substâncias pseudoplásticas, visto que as moléculas se desorientam depois que a força de cisalhamento acaba. Uma força de cisalhamento muito alta aplicada no material viscoso estrutural transforma o fluxo laminar em turbulento e resulta em um aumento da viscosidade. O comportamento pseudoplástico é muito comum na maioria dos fluidos não Newtonianos, principalmente em emulsões e gomas. As soluções de gomas são dispersões e/ou agregados de moléculas hidratadas e seu comportamento reológico também é função da flexibilidade da cadeia macromolecular, concentração do polímero, da temperatura e da taxa de deformação (BRISCOE, LUCKHAM e ZHU, 1998).

A goma Xantana é um polieletrólito que possui propriedades reológicas únicas, tais como alta viscosidade a baixas concentrações e baixas taxas de deformações, além de possuir alta pseudoplasticidade. Polieletrólitos são macromoléculas que contém um grande número de grupos ionizáveis que dão comportamento reológico diferente dos biopolímeros neutros (SILVA e RAO, 1992).

Existe uma correlação entre as características organolépticas das soluções de hidrocolóides e seus comportamentos reológicos. Medidas da viscosidade das soluções a várias taxas de cisalhamento mostram uma relação entre o formato da curva e o grau 
de viscosidade. As soluções de hidrocolóides podem ser agrupadas em três categorias: viscosas, levemente viscosas e não viscosas, dependendo da configuração da curva.

Para os fluidos pseudoplásticos é utilizada a equação da Lei de Potência com dois parâmetros (BEZERRA, 2000):

$$
\tau=\mathrm{K} \dot{\gamma}^{\mathrm{n}}
$$

onde $\mathrm{K}$ é o índice de consistência, $\mathrm{n}$ é o índice de comportamento, $\tau$ é a tensão de cisalhamento e $\dot{\gamma}$ é a taxa de deformação. Para $\mathrm{n}>1$ o fluido é classificado como dilatante, para $\mathrm{n}<1$ o fluido é considerado pseudoplástico e para $\mathrm{n}=1$ o fluido tem comportamento Newtoniano.

Fluidos dilatantes mostram um aumento na viscosidade com um aumento da taxa de deformação e geralmente alcança o ponto onde o fluido se torna sólido. O meio disperso é insuficiente para saturar o sistema. A viscosidade aumenta com um aumento da força de cisalhamento ou do fluxo. A viscosidade aparente cresce com o aumento da taxa de deformação, geralmente atingindo uma inclinação limite (Fig. 2.3).

Os fluidos tixotrópicos são formalmente definidos como a transição reversível gel-solução-gel e é causada pela construção de uma estrutura definitiva dentro do material.

A estrutura gel sob agitação se torna solução, quando se mantém sem perturbação, se torna gel novamente. Este fenômeno é baseado na quebra de forças ativas entre as partículas.

Este é caracterizado pelo fato de que a agitação produz uma diminuição da viscosidade e a viscosidade original só é recuperada depois de um período de descanso. Este tipo de sistema mostra um efeito histerese na curva do fluxo, a qual é obtido pelo aumento da taxa de deformação e depois, sem parar, a taxa decresce. Então se pode deduzir que a viscosidade, a qualquer taxa de deformação particular, vai depender da força total de cisalhamento prévio que foi submetida.

Algumas substâncias tixotrópicas mostram uma diminuição da viscosidade em um período de dias, enquanto outras levam apenas alguns segundos ou menos para alcançar o valor final.

Fluidos reopéticos mostram um aumento da viscosidade com uma força de cisalhamento constante. Este sistema também é dependente do tempo, mas de maneira contrária ao fluxo tixotrópico. Com o tempo, a substância vai recuperar seu estado 
líquido original se não ocorrer uma mudança de fase ou química. Apresentam, como os fluidos tixotrópicos, curva de histerese, mas sua viscosidade aumenta com o tempo.

\subsubsection{Medidas Reológicas de Fluidos}

A viscosidade é medida por reômetros que fornecem vários valores, obtendo-se o gráfico de taxa de deformação e tensão de cisalhamento( $\tau$ vs $\dot{\gamma}$ ), avaliando o comportamento de um fluido para então adotar um modelo de comportamento reológico. Os reômetros podem ser rotacionais ou capilares.

Os sistemas capilares são versáteis e fáceis de usar, onde o fluido escoa no interior de um tubo circular, devido à diferença de pressão da entrada e da saída, que podem ocorrer por gravidade ou por meios mecânicos. A medida das viscosidades relativas dos fluidos Newtonianos podem ser determinadas com precisão com estes instrumentos e calculadas pela lei de Poiseuille:

$$
\mu=\frac{\left(\frac{d \Delta P}{4 L}\right)}{\left(\frac{32 Q}{\pi d^{3}}\right)}=\frac{\tau}{\dot{\gamma}}
$$

onde d é o diâmetro interno do tubo, L é o comprimento do tubo, Q é a vazão, $\Delta \mathrm{P}$ é a queda de pressão ao longo de $\mathrm{L}, \dot{\gamma}$ é a taxa de deformação, $\mu$ é a viscosidade e $\tau$ é a tensão de cisalhamento.

Os sistemas rotacionais medem a resistência em um agitador como uma medida de viscosidade do fluido analisado. A maior vantagem do reômetro rotacional é que a medida da viscosidade pode ser feita continuamente por um período extenso de tempo sob controladas taxas de deformação e tensão de cisalhamento. Mudanças da viscosidade com o tempo podem ser facilmente seguidas. Fluidos não Newtonianos que tem suas viscosidades aparentes variadas com a taxa de deformação, podem ser estudadas sob condições experimentais extremamente reguladas. Os reômetros rotacionais podem ser de cilindros concêntricos, placas planas pararelas, cone e placas.

Os reômetros rotacionais de cilindros concêntricos mantêm uma velocidade de rotação constante a certa taxa de deformação e a tensão de cisalhamento é obtida através da medida do torque no cilindro de medida, que pode ser fixo ou rotativo. São projetados para causar cisalhamento no fluido localizado entre dois cilindros concêntricos sendo que um gira e o outro permanece estacionário permitindo obter 
curvas reológicas, pelo estabelecimento de várias velocidades angulares do cilindro rotativo e do torque correspondente detectado no cilindro de medida (BEZERRA, 2000).

Este tipo de reômetro é muito utilizado no campo dos hidrocolóides, obtendose a viscosidade aparente das gomas.

\subsection{Microfiltração}

\subsubsection{Conceituação e Fenomenologia}

A microfiltração (MF) é um processo que utiliza o gradiente de pressão como força motriz, junto a uma superfície permeável (membrana) que visa a separação de partículas. As membranas utilizadas possuem microporos que separam partículas com um tamanho na faixa de 0,1-10 $\mu \mathrm{m}$. Portanto, a microfiltração está entre a ultrafiltração e a filtração convencional, que não possui operação com membrana.

O que distingue os processos de microfiltração, ultrafiltração, nanofiltração e osmose reversa por membrana é a aplicação da pressão hidráulica e o tamanho da partícula. Entretanto a própria natureza da membrana controla quais componentes serão permeados e quais serão retidos.

A separação está baseada no efeito peneira molecular e macromolecular. sendo limitado, principalmente à superfície da membrana. A estrutura dos microporos da membrana deveria ter uma estreita distribuição do tamanho do poro para assegurar a retenção quantitativa das partículas de um determinado tamanho e tipo. Outra característica importante é a alta porosidade das membranas que conduzem a elevadas taxas de filtração a pequenas diferenças de pressão (RIPPERGER e ALTMANN, 2002).

O projeto do sistema de microfiltração é um processo complexo que requer um conhecimento em particular, das características físicas e químicas da solução de alimentação, do fluxo do produto e da membrana semipermeável, tão bem quanto a economia associada com a compra, instalação e operação do módulo de filtração.

Segundo Zeman e Zydney (1996), a membrana é apenas um componente deste sistema complexo. Os métodos atuais de microfiltração incluem bombas, recipiente de alimentação, tubulação e as conexões associadas; monitores necessários, unidades de controle para pressão, temperatura, taxa de fluxo e o mais importante: o módulo da membrana. 
Nos processos de microfiltração e ultrafiltração, o gradiente de pressão através da membrana deve conduzir o solvente e as pequenas espécies através de seus poros, enquanto as moléculas mais largas devem ser retidas. Assim, uma vazão de alimentação é dividida em duas, a vazão do concentrado que será enriquecido de macromoléculas retidas e a vazão de permeado que será deficiente em macromoléculas.

Há algumas limitações nos processos com membranas. No caso da microfiltração e ultrafiltração, raramente é a pressão osmótica das macromoléculas retidas que limita o processo, mas sim a baixa taxa de transferência de massa obtida com as macromoléculas concentradas e a alta viscosidade que dificulta o bombeamento do concentrado (CHERYAN, 1998).

A microfiltração com a utilização de uma membrana é a tecnologia mais antiga. Começou no início do século passado com a preparação dos seus microporos de material sintético baseado em celulose.

Segundo Ripperger e Altmann (2002), as propriedades dos microporos das membranas são determinadas pelo processo e pelos materiais utilizados. As membranas de polímero são geralmente usadas nos procedimentos de filtração. Estes tipos de membranas são favoráveis em termos da relação custo/benefício. As membranas de microfiltração (MF) de materiais inorgânicos como a cerâmica, o metal e o carbono são utilizados, quando há a necessidade, por exemplo, de alta estabilidade térmica.

Existem dois tipos de microfiltração que são muito empregados em indústrias, o método perpendicular e o tangencial.

$\mathrm{Na}$ microfiltração perpendicular, a vazão da alimentação ocorre perpendicularmente a superfície da membrana e as partículas concentradas se acumulam nesta, formando uma camada de filtrado sólido (figura 2.5). A espessura desta camada aumenta com o tempo e a taxa de permeabilidade decresce. Eventualmente o filtro da membrana com esta camada causa uma baixa taxa de filtração, promovendo tanto a limpeza deste quanto sua troca, tornando o método pouco econômico. Este tipo de incrustação pode ser reduzida com a microfiltração tangencial (SCOTT, 1995).

As incrustações ocorrem tanto na microfiltração tangencial como na perpendicular. Esta última ocorre com maior facilidade, devido ao fluxo chegar diretamente na membrana, portanto a microfiltração perpendicular é utilizada para líquido com concentração muito baixa de sólido. Quase todo líquido é filtrado em uma etapa de filtração com pequeno volume de concentrado. Já na microfiltração tangencial é recomendada para líquido com alta concentração de sólidos. 
O processo tangencial é mais complexo que o perpendicular, pois requer considerações de três processos distintos de fluxos, a solução de alimentação, o permeado e o concentrado. Já o perpendicular tem apenas os fluxos de alimentação e o permeado, cada um com a mesma vazão mássica (ZEMAN e ZYDNEY, 1996).

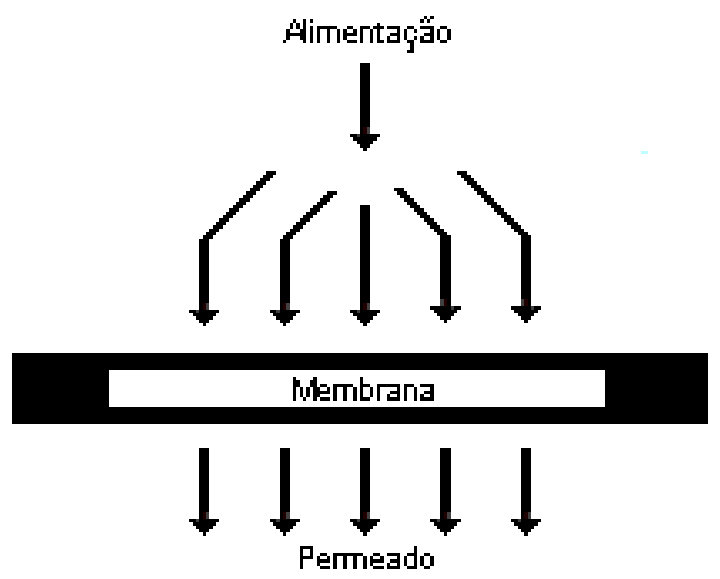

Figura 2.5: Microfiltração Perpendicular - Fonte: Zeman e Zydney (1996), Microfiltration and Ultrafiltration, Principles and Applications.

\subsubsection{Microfiltração Tangencial}

A microfiltração tangencial ocorre tangencialmente a uma superfície permeável (membrana) (Figura 2.6) e é usada para a produção de líquidos puros, para a concentração de suspensões, para recuperar produtos e para a regeneração de processos líquidos. A microfiltração se tornou um processo estabelecido para a separação de micropartículas, bactérias e emulsões. Freqüentemente uma concentração muito alta de uma mistura fluida pode ser alcançada, por isso a microfiltração tangencial é normalmente utilizada em combinação com outros processos de separação (RIPPERGER e ALTMANN, 2002). 


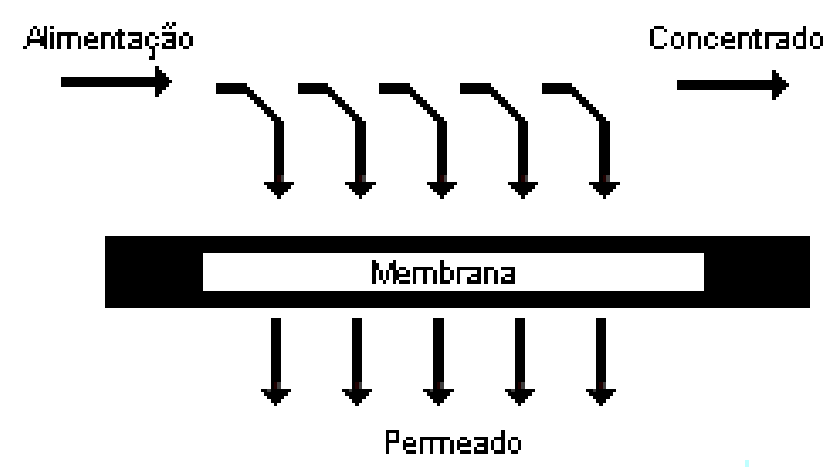

Figura 2.6: Microfiltração Tangencial - Fonte: Zeman e Zydney (1996), Microfiltration and Ultrafiltration, Principles and Applications.

Quando uma corrente, tangencial ou perpendicular é filtrada, pode ocorrer incrustação da membrana que é causada pela constrição do tamanho do poro, bloqueio do poro, ou deposição de células, restos de células ou outras partículas, tais como macromoléculas no topo da superfície da membrana. Isto faz com que a vazão de permeado diminua (CZEKAJ, LÓPEZ e GÜELL, 2001).

No processo de microfiltração tangencial a alimentação é bombeada sem interrupção através de uma membrana com uma velocidade e pressão a ser determinada segundo às necessidades de cada experimento. Uma baixa velocidade de alimentação evita uma rápida formação da camada de polarização e proporciona um controle da incrustação do módulo.

Neste tipo de filtração, o fluido a ser filtrado é transferido através da membrana devido a uma diferença de pressão. O fluxo tangencial reduz a formação de camada de polarização no meio filtrante, sendo possível obter um fluxo de filtrado quase permanente por muito tempo. Hoje este modo de operação é padrão em muitas aplicações em membrana para as áreas médicas e técnicas, conhecida também como filtração dinâmica.

Os processos da filtração tangencial são principalmente determinados pela formação desta camada de polarização na membrana. Um melhor conhecimento da formação da camada e a deposição de partículas na membrana poderia resultar em um uso mais econômico da filtração tangencial em muitas aplicações técnicas (RIPPERGER e ALTMANN, 2002). 
Segundo Mãnttãri el al. (2000), a microfiltração tangencial é utilizada em diferentes tipos de indústrias, demonstrando uma extensa aplicação desta técnica de separação em:

- Clarificação de sucos de fruta, vinho, sidra e vinagre;

- Separação de gordura e remoção bacteriana de leite;

- Remoção do fermento da cerveja;

- Clarificação de soro antes de outra etapa de filtração por membrana, como ultrafiltração ou eletrodiálise;

- Tratamento da água potável sem adição de substâncias químicas (redução da carga microbiana);

- Filtração de caldos de fermentação;

- Tratamento de águas residuárias de processos metalúrgicos gerados de misturas água/óleo.

O transporte de material na parede da membrana e a limitação da formação da camada de polarização pelo fluido são os fatores principais nos processos de filtração tangencial. Estes fenômenos hidrodinâmicos podem ser quantificados por diferentes parâmetros, tais como velocidade tangencial, número de Reynolds, tensão de cisalhamento ou taxa de deformação na parede da membrana, pressão transmembrana, resistência da membrana e da camada de polarização e efeitos de superfície da partícula. Entre estes parâmetros, a velocidade tangencial é a mais utilizada, especialmente quando a influência qualitativa do fluxo tangencial no permeado é investigada, mas quando são desenvolvidas correlações para representar este fluxo, qualquer parâmetro é utilizado. O resultado dos estudos do ponto de vista qualitativo é o aumento do filtrado com o aumento da velocidade tangencial, mas em alguns casos, o permeado possui velocidade tangencial independente.

Carrère, Schaffer e René (1998) estudaram os efeitos de parâmetros operacionais dos fluxos permeáveis em estado quase permanente na microfiltração de uma solução de goma Guar. Concluíram que o fluxo depende principalmente da concentração e velocidade do fluxo tangencial, enquanto a pressão através da membrana e o tamanho do poro tiveram muito pouco efeito. A camada de concentração de polarização dinâmica formada à superfície da membrana controlou o fluxo permeável.

Um estudo qualitativo no efeito da pseudoplasticidade na transferência de massa na ultrafiltração foi desenvolvido por Aimar (1987). Considerou que fluidos 
pseudoplásticos podem criar melhor transferência de massa do que fluidos Newtonianos nos quais têm a mesma viscosidade em repouso, pois os fluidos pseudoplásticos possuem maior taxa de deformação e menor viscosidade na parede.

A camada de concentrado adjacente a superfície da membrana contra corrente pode ter reologia e propriedades mecânicas substancialmente diferentes da solução mais diluída (CHARCOSSET E CHOPLIN, 1996).

O modelo de concentração de polarização permite o cálculo do fluxo de permeado, quando o coeficiente de transferência de massa, $\mathrm{k}$, e a concentração na parede da membrana, $\mathrm{C}_{\mathrm{w}}$, são conhecidos:

$$
J=k \log \left(\frac{C_{w}}{C_{b}}\right)
$$

onde $\mathrm{C}_{\mathrm{b}}$ é a concentração no seio do escoamento.

A equação 2.4 indica que se $\mathrm{k}$ e $\mathrm{C}_{\mathrm{w}}$ são constantes então o decréscimo do fluxo deve ser proporcional ao logaritmo da concentração. Para fluidos Newtonianos, a correlação mais popular utilizada é baseada na equação de Lévêque obtida para transferência de massa laminar. Para tubos cilíndricos, esta correlação tem a seguinte forma:

$$
k=\left(\frac{3 D^{2}}{4 L}\right)^{1 / 3}\left(\frac{8 \mu}{D}\right)^{1 / 3}
$$

onde $\mathrm{D}$ é o coeficiente de difusão, $\mu$ é a viscosidade e L é o comprimento do tubo.

Para fluidos não Newtonianos, Pritchard (1990 apud Charcosset e Choplin, 1996), propôs uma expressão para o coeficiente de transferência de massa laminar que incorpora o efeito da concentração dependente do comportamento reológico pseudoplástico baseado no modelo integral de Field (1990):

$$
\begin{gathered}
k=\left(\frac{3 D^{2}}{4 L}\right)^{1 / 3}\left(\frac{3 n_{b}+1}{4 n_{b}} \frac{8 \mu}{d}\right)^{B}\left(\frac{K_{b}^{1 / n_{b}}}{K_{w}^{1 / n_{w}}}\right)^{0,13} \\
\mathrm{~B}=\frac{2 \mathrm{n}_{\mathrm{b}}}{3\left(\mathrm{n}_{\mathrm{b}}+\mathrm{n}_{\mathrm{w}}\right)}
\end{gathered}
$$

onde $\mathrm{n}_{\mathrm{b}}, \mathrm{K}_{\mathrm{b}}, \mathrm{n}_{\mathrm{w}}$ e $\mathrm{K}_{\mathrm{w}}$ são índices do comportamento do fluxo e consistência do fluido de volume e parede, respectivamente. B é o expoente para a taxa de deformação na parede ou termo da velocidade axial. Esta equação é uma ferramenta para entender o aumento do coeficiente de transferência de massa observado durante a concentração das soluções 
de goma Xantana. Entretanto, a discrepância entre o expoente da velocidade axial observada, predita e o fluxo é observado, embora o coeficiente de difusão D e o valor 0,13 são ajustados para dar o melhor ajuste. Além disso, esta correlação é muito mais questionável para condições onde $\mathrm{n}_{\mathrm{w}} \neq \mathrm{n}_{\mathrm{b}}$.

Muitas correlações tem sido desenvolvidas para a transferência de calor para fluidos não Newtonianos, por exemplo, usualmente para condições, onde $\mu_{\mathrm{w}}<\mu_{\mathrm{b}}$.

Isto não é paralelo às condições na parede da membrana, onde $\mu_{\mathrm{w}}>\mu_{\mathrm{b}}$. Além do mais, como as propriedades pseudoplásticas do fluido são relativamente independentes da temperatura, estas correlações só consideram o caso da camada limite, tendo o mesmo grau de pseudoplasticidade que o volume do fluido.

Charcosset e Choplin (1996) propuseram uma nova equação empírica para o coeficiente de transferência de massa baseada na transferência de calor para condições de resfriamento que pode incorporar o índice do efeito do comportamento dependente do fluxo de concentração. O coeficiente de transferência de massa é expresso como:

$$
k=\left(\frac{3 D^{2}}{4 L}\right)^{1 / 3}\left(\frac{3 n_{b}+1}{4 n_{b}} \frac{8 \mu}{D}\right)^{1 / 3}\left(\frac{\mu_{P N}\left(C_{b}\right)}{\mu_{a}\left(C_{w)}\right.}\right)^{0,27}
$$

onde D é o coeficiente de difusão do soluto, L é o comprimento da membrana, $\mathrm{n}_{\mathrm{b}}$ é o índice de comportamento no seio do escoamento, u é a velocidade, $\mu_{\mathrm{PN}}$ é a viscosidade equivalente ao processo Newtoniano, $\mu_{\mathrm{a}}$ é a viscosidade aparente, $\mathrm{C}_{\mathrm{b}}$ é a concentração do soluto no seio do escoamento e $\mathrm{C}_{\mathrm{W}}$ é a concentração do soluto na parede.

O processo Newtoniano de viscosidade equivalente na concentração da mistura e a viscosidade aparente da parede na concentração da superfície da membrana são expressas como:

$$
\mu_{\mathrm{PN}}\left(\mathrm{C}_{\mathrm{b}}\right)=\frac{\tau_{\mathrm{w}}\left(\mathrm{C}_{\mathrm{b}}\right) \mathrm{d}}{8 \mathrm{u}} \mu_{\mathrm{a}}\left(\mathrm{C}_{\mathrm{w}}\right)=\frac{\tau_{\mathrm{w}}\left(\mathrm{C}_{\mathrm{w}}\right)}{\gamma_{\mathrm{w}}\left(\mathrm{C}_{\mathrm{w}}\right)}
$$

onde $\tau_{\mathrm{w}}$ e $\dot{\gamma}_{w}$ são a tensão de cisalhamento e a taxa de deformação na parede da membrana e 8u/d é o parâmetro característico do fluxo (CHARCOSSET E CHOPLIN, 1996).

A presença de uma camada limite pseudoplástica conduziu a expoentes mais altos do número de Reynolds nas correlações do fluxo permeável de estado permanente, porque um aumento da velocidade axial conduz a uma diminuição da viscosidade aparente na parede e o aumento da transferência de massa. Além disso, Aimar (1987) esboçou um efeito mais acentuado da velocidade axial quando o fluido tratado era mais 
pseudoplástico: uma maior sensibilidade da viscosidade aparente na taxa de deformação foi obtida com valores mais baixos do índice de comportamento. Quando experiências foram feitas a várias concentrações, o expoente do parâmetro hidrodinâmico variou.

A velocidade tangencial (v), é uma velocidade média e é geralmente determinada pela vazão do concentrado $Q_{r}$. Para membranas tubulares, sua expressão é:

$$
v=\frac{\mathrm{Q}_{\mathrm{r}}}{\mathrm{N} \pi\left(\mathrm{d}^{2} / 4\right)}
$$

onde d é o diâmetro interno e $\mathrm{N}$ o número de tubos ou canais.

O número generalizado de Reynolds para lei de potência para fluidos é:

$$
\operatorname{Re}^{\prime}=\frac{d^{n} v^{2-n} \rho}{8^{1-n} K}\left(\frac{4 n}{1+3 n}\right)^{n}
$$

onde $\rho$ é a densidade do fluido, $v$ a velocidade tangencial média e $\mathrm{K}$ e $\mathrm{n}$ são índices de consistência e de comportamento do fluido, respectivamente. Para o cálculo deste número, geralmente são levadas em conta as características reológicas do concentrado e também a sua viscosidade para fluidos Newtonianos. A camada de polarização produz a presença de uma camada mais viscosa (ou de uma camada com diferentes índices de comportamento e consistência) na parede da membrana.

A expressão para a taxa de deformação na parede para fluxos laminares em tubos cilíndrico $\dot{\gamma}_{w}$ é:

$$
\dot{\gamma}_{\mathrm{w}}=\left(\frac{3 \eta_{\mathrm{b}_{1}}+1}{4 \eta_{\mathrm{b}_{1}}}\right) \frac{8 \mathrm{v}}{\mathrm{d}}
$$

onde $\mathrm{n}_{\mathrm{bl}}$ é o índice de comportamento na camada limite, $v$ é a velocidade tangencial do fluxo e d é o diâmetro da membrana.

De acordo com o resultado, o índice de comportamento nesta expressão é a concentração média na camada limite na parede da membrana.

A tensão de cisalhamento na parede $\tau_{\mathrm{w}}$, é calculada pelas medidas de queda de pressão, na forma:

$$
\tau_{\mathrm{w}}=\frac{\Delta \mathrm{Pd}}{4 \mathrm{~L}}
$$

onde $\Delta \mathrm{P}$ é a queda de pressão axial ao longo das membranas, $\mathrm{L}$ o comprimento da membrana e d é o diâmetro interno. 
Entre estes quatro parâmetros, a velocidade tangencial é muito utilizada, por sua fácil medição. O número de Reynolds é geralmente usado com o modelo da teoria de filme onde o coeficiente de transferência de massa é calculado da equação de Lévêque (Eq. 2.5) (ZEMAN e ZYDNEY, 1996). A taxa de deformação na parede aparece em alguns modelos teóricos desenvolvidos para filtração tangencial (por exemplo modelo induzido de difusão de cisalhamento), mas sua determinação sob condições de fluxo turbulentos é difícil. Pode ser calculado da equação 2.14, mas é imperativo para introduzir os valores dos parâmetros reológicos (ou viscosidade) na parede da membrana e não no volume como é normalmente realizado. A tensão de cisalhamento na parede é muito fácil de ser determinada e inclui o aumento da viscosidade na superifície da membrana. Além disso, de acordo com Gésan-Guiziou et al. (1999), $\tau_{\mathrm{W}}$ é o parâmetro hidrodinâmico efetivo considerado para filtração da camada de polarização. (CARRÉRE, 2000).

$$
\dot{\gamma}=\left(\frac{\tau_{\mathrm{w}}}{\mathrm{K}_{\mathrm{w}}}\right)^{1 / \mathrm{n}_{\mathrm{w}}}
$$

onde $\tau_{\mathrm{W}}$ é a tensão de cisalhamento na parede, $\mathrm{K}_{\mathrm{W}}$ é o índice de consistência na parede e $\mathrm{n}_{\mathrm{W}}$ é o índice de comportamento na parede.

Os modelos para a descrição dos processos de microfiltração tangencial podem ser empíricos e físicos. A atenção maior está nos modelos físicos, porque a consideração empírica é útil na prática, mas não é útil para estender o entendimento dos processos de filtração tangencial. Os modelos físicos são divididos em modelos macroscópicos e microscópicos. A aproximação macroscópica considera o sistema de partícula como uma quantidade contínua, enquanto os modelos microscópicos consideram o comportamento de uma única partícula durante a filtração. Ambas as aproximações reduzem o elevado número da influência de parâmetros para os seguintes mecanismos físicos:

- Hidrodinâmica das partículas;

- Difusão da partícula;

- Interação da partícula e efeitos da superfície.

Os primeiros modelos macroscópicos da filtração tangencial, nos anos setenta, foram baseados na difusão e concentração de polarização na membrana. Estes modelos consideram os parâmetros que afetam o fluxo no caso de sólidos suspensos com os modelos matemáticos baseados em difusão. O movimento de difusividade das partículas 
causa um transporte oposto ao transporte convectivo do filtrado. No estado estacionário ambos os mecanismos de transporte estão em equilíbrio. A taxa de filtração pode ser calculada como segue:

$$
v_{F}=\frac{D}{\delta} \ln \left(\frac{C_{M}-C_{P}}{C_{F}-C_{P}}\right)=k \ln \left(\frac{C_{M}-C_{P}}{C_{F}-C_{P}}\right)
$$

O coeficiente de transferência de massa $\mathrm{k}$ é a relação do coeficiente de difusão $\mathrm{D}$ e a espessura da camada limite de concentração $\delta$. A concentração do componente a ser separado no líquido permeável $\mathrm{C}_{\mathrm{P}}$ é determinado pelas características da membrana. $O C_{F}$ é a concentração na alimentação. A concentração na superfície da membrana $C_{M}$ é a concentração máxima de um sistema de partícula do fluxo. Os modelos de difusão macroscópicos são freqüentemente um caso incerto de modelos semi-empíricos e empíricos, porque eles não consideram só efeitos de corrente térmica e difusão turbulenta. Este modelo inclui todos os efeitos da interação, hidrodinâmica e difusão das partículas, em um coeficiente de difusão D.

O ponto de partida de modelos microscópicos é a consideração das forças que agem em uma única partícula. De acordo com McLaughlin (1991) uma avaliação quantitativa das forças hidrodinâmicas mostra que especialmente a força de arraste e a força peso influenciam principalmente no depósito de partículas na membrana.

A uma alta taxa de filtração a força de arraste é maior do que a força peso em uma extensa gama de partículas. Com a diminuição da taxa de filtração, tende-se ao equilíbrio entre a força peso e a força de arraste do filtrado, inicialmente prevalecendo o depósito de pequenas partículas.

Há pelo menos quatro tipos diferentes de mecanismos nos quais podem ser responsáveis pelo transporte reverso: o peso inercial, a difusão de tensão induzida, a difusão Browniana e o transporte na superfície. Baseado nestes mecanismos, quatro diferentes modelos tem sido desenvolvidos nos quais predizem o fluxo limite para a operação de microfiltração. O fluxo limite é a pressão independente do fluxo, obtida quando altas pressões transmembranas são aplicadas. É dependente da velocidade tangencial, temperatura, propriedades de suspensão na alimentação e da geometria do módulo da membrana (SAMUELSSON et al, 1997).

Um estudo experimental de Rushton, Hosseini e Hassan (1980) relativo a fragmentos de sais de cálcio e carbonato de magnésio, mostrou que para uma concentração superior a um certo valor inicial, a resistência específica cairá com a 
diminuição da concentração. Os autores assumem que o aumento da concentração conduzirá ao aumento da freqüência de partículas adicionadas no depósito da camada de polarização. Além disso, a espessura desta é analisada em termos de um arranjo de partículas sobre as quais só podem ser vistas se o número destas que chegam simultaneamente à camada, ainda em formação, for limitado. A diminuição na resistência da camada de polarização, quando a concentração é aumentada, é colocada sob um arranjo desordenado de partículas durante a constituição do depósito, assim conduzindo a uma maior porosidade.

Vários estudos estão baseados no conceito de arranjo de partícula dentro da camada; as conclusões que estes estudos chegaram são ainda questionáveis e às vezes contraditórios. Estas contradições podem ocorrer devido aos diferentes tipos de partículas e às várias condições operacionais de cada processo. (HAMACHI e MIETTON-PEUCHOT, 1999).

\subsubsection{Membrana}

Membrana é uma barreira fina através da qual solventes e solutos são transportados seletivamente. Pode ser constituída por um polímero orgânico ou inorgânico, metal, cerâmica, camadas químicas ou mesmo líquidos ou gases. A aplicação de uma força direcionada (por exemplo: pressão, concentração, potencial elétrico, etc.) pressionam certos elementos da solução através da membrana. Esta membrana controla a taxa relativa do transporte de várias espécies. Como toda separação, proporciona um produto com baixas concentrações de um determinado componente e um segundo produto com altas concentrações deste componente.

O desempenho da membrana é definido em termos de dois fatores simples, fluxo e retenção ou seletividade. Fluxo ou taxa de permeado é o fluxo volumétrico de fluido que passa através da membrana por unidade de área por tempo. Seletividade é uma medida da taxa relativa de permeado de vários componentes através da membrana. 
Há, em particular, uma necessidade para predizer um método geral que tem como ponto de partida as propriedades físico-químicas dos materiais a serem separados.

Nos sistemas de ultrafiltração por membrana, a concentração de polarização determina o fluxo de filtração. Esta polarização é construída de soluto perto da superfície da membrana devido ao transporte convectivo-difusivo de soluto na camada limite. Para entender o fenômeno de transporte na superfície da membrana é preciso desenvolver modelos matemáticos para o fluxo de fluidos e a equação da continuidade de solutos. Para aplicar estes modelos é necessário fazer algumas simplificações, tais como: a velocidade de permeabilidade da parede é constante ao longo do eixo axial; o campo de fluxo tem aproximadamente a forma reduzida da equação de momento; as propriedades de transporte do fluido são assumidas constantes. Para os cálculos são utilizadas correlações empíricas para a pressão osmótica e viscosidade, que só serão aplicáveis para condições específicas de soluto e solução.

Para predizer a taxa de ultrafiltração, três propriedades da dispersão devem ser consideradas: o coeficiente de gradiente de difusão, a pressão osmótica e a viscosidade. Para qualquer modelo matemático ser efetivo, deve ser feito um estudo detalhado da maneira em que estas propriedade variam com a concentração da partícula.

A pressão osmótica é uma propriedade chave nos processos de ultrafiltração, pois controla a distribuição espacial das partículas na camada de concentração polarizada e também a taxa de permeabilidade (BOWEN e WILLIAMS, 2001).

As membranas são usadas em vários tipos de separação; misturas de gases e vapores, líquidos miscíveis, sólido/líquido, líquido/líquido e sólidos dissolvidos.

O principal aspecto que diferencia a separação por membrana de outras técnicas de separação é o uso de outra fase, a membrana. Esta fase, líquida, sólida ou gasosa, introduz uma interface entre as duas fases envolvidas na separação e pode proporcionar vantagens na eficiência e seletividade.

As membranas podem ser classificadas segundo vários aspectos:

a) Natural ou sintética;

b) Estrutura porosa ou não porosa;

c) Ação de mecanismo: adsortiva ou difusiva, troca iônica, osmótica ou membranas não seletivas.

As membranas podem modificar, fisicamente ou quimicamente, as espécies que estão sendo permeadas (com membranas de troca iônica ou biofuncionais), a 
corrente de condução elétrica, a permeabilidade preventiva, ou podem regular a taxa de permeabilidade.

Segundo Cheryan (1998), existem dois tipos de membranas: as membranas produzidas com polímeros e as membranas inorgânicas. Dentre as de polímeros destacam-se:

a) Acetato de celulose

Este é um material clássico para membranas, usado pelos pioneiros da tecnologia moderna para criar as membranas revestidas.

Há várias vantagens na utilização deste tipo de membrana como por exemplo:

- Hidrofilicidade, fator muito importante para minimizar a incrustação da membrana;

- Ampla faixa de tamanhos dos poros podem ser produzidos, da osmose reversa a microfiltração, com altos fluxos;

- $\quad$ São fáceis de serem manufaturadas;

- Baixo custo

As desvantagens são:

- $\quad$ Baixas temperaturas de utilização, no máximo $40^{\circ} \mathrm{C}$;

- $\quad$ Restrição do pH, de 3 a 6;

- Este tipo de material não tem resistência ao cloro. O cloro oxida o acetato de celulose e enfraquece a membrana, abrindo seus poros. O cloro é um sanitizador universal muito utilizado nas indústrias, dificultando a aplicação deste tipo de membrana;

- $\quad$ È muito susceptível ao ataque de microrganismos, devido a sua estrutura;

b) Membranas de poliamida

Este tipo de membrana tem os mesmos problemas associados à membrana citada acima, exceto que sua tolerância ao pH é maior, mas tem uma tolerância bem menor ao cloro do que a membrana de acetato de celulose.

c) Membranas polissulfonadas

A família das membranas polisulfonadas (PS) e polietersulfonadas (PES) são amplamente usadas em microfiltração e ultrafiltração devido às seguintes características favoráveis:

- $\quad$ Altos limites de temperatura, acima de $75^{\circ} \mathrm{C}$ (PS) e $125^{\circ} \mathrm{C}$ (PES). Esta é uma vantagem em fermentação, biotecnologia e em algumas aplicações de processos onde a viscosidade é muito baixa a altas temperaturas. Quanto 
maior a temperatura, maior cuidado deve-se ter com os parâmetros de operação, tais como $\mathrm{pH}$, pressão e o processo de limpeza;

- $\quad$ Alta tolerância ao pH, de 1 a 13;

- Boa resistência ao cloro;

- Facilmente manufaturada em várias configurações e módulos;

- Ampla faixa de tamanhos de poros;

A principal desvantagem destes tipos de membranas é o baixo limite de pressão e a hidrofobicidade, que leva a uma aparente tendência de interagir fortemente com uma variedade de solutos, fazendo com que ocorra uma maior incrustação.

Outros tipos de membrana poliméricas disponíveis nas indústrias são as de nylon, politetrafluoretileno, polipropileno, celulose regenerada, policarbonada.

Dentre as membranas inorgânicas, destacam-se as cerâmicas que são ótimos materiais para a produção dos tubos de filtração, pois permite alta velocidade de alimentação da filtração tangencial, resultando em um regime turbulento. A turbulência previne a formação de incrustações e garante um fluxo altamente permeável.

Vantagens das membranas de cerâmica comparadas com as de polímeros incluem:

- Resistência a temperaturas acima de $280^{\circ} \mathrm{C}$ (especialmente modelos desenvolvidos e sistemas acima de $700^{\circ} \mathrm{C}$ );

- Boa resistência a corrosão: resistente a solventes orgânicos e extensa faixa de $\mathrm{pH}$;

- Membranas de cerâmica são apropriadas para limpeza e esterilização;

- Longa vida operacional;

- Quimicamente inerte: extensa faixa de aplicações na indústria química;

As vantagens citadas acima mostram que este tipo de membrana tem muitas aplicações nos processos de separação, como por exemplo misturas de tinta/água, emulsões óleo/água, tratamento de esgoto, etc.

As desvantagens em relação as de polímeros são:

- $\quad$ Frágil deve ser manuseada com cuidado;

- A taxa superfície área/volume é baixa conduzindo a sistemas com maiores dimensões;

- Segundo Scott (1995), o investimento inicial em membranas de cerâmica é alto; 
As membranas inorgânicas e de cerâmicas, geralmente, são encontradas na forma tubular, sendo de canal simples ou de multicanal. Cuidados especiais devem ser tomados com seus O-rings, gaxetas e tampões que são utilizados para manter seus elementos em suas posições.

Em todos os módulos inorgânicos, a alimentação flui dentro dos canais, enquanto o permeado flui através do suporte.

Titanio $\left(\mathrm{TiO}_{2}\right)$ é sintetizado em material poroso dentro dos tubos para formar uma membrana de microfiltração permanente com tamanho de poro de $0,1 \mu \mathrm{m}$. Devido a sua excelente química e a alta resistência à temperatura, são utilizadas em processos de alta temperatura, filtração crítica de lubrificação de óleos. As membranas de prata são atacadas pelos ácidos sulfúrico e nítrico. Como a maioria das membranas inorgânicas é muito caras. Existem também as membranas de alumínio.

Apesar do vasto número de materiais de membranas que tem sido estudado, há poucas que tem sucesso comercialmente. Para as aplicações de ultrafiltração e microfiltração as polietersulfonadas são muito utilizadas, bem como a polisulfonada, a polipropileno e as de cerâmica. Apesar das limitações aparentes do acetato de celulose, se mantém no mercado, devido a baixa tendência de incrustação e ao baixo custo.

O maior limite na tecnologia de membranas é a incrustação. Esta incrustação se manifesta com um declínio da vazão com o tempo de operação. Este declínio ocorre quando todos os parâmetros de operação, tal como pressão, temperatura e concentração da alimentação se mantém constantes.

A incrustação não deve ser confundida com a concentração de polarização. A primeira é caracterizada pela irreversibilidade do declínio da vazão e ocorre devido às interações entre a membrana e o soluto. Já os efeitos da concentração de polarização podem ser reversíveis quando ocorre a diminuição da pressão transmembrana, quando a concentração da alimentação é aumentada ou com o aumento da velocidade tangencial ou turbulência (CHERYAN, 1998).

De acordo com Belfort, Davis e Zydney (1994), incrustações coloidais ocorrem em dois estágios: incrustações internas e externas. A incrustação interna é causada pela deposição ou adsorção de pequenas partículas e macromoléculas dentro da estrutura interna dos poros. Dois modelos tem sido propostos para descrever a incrustação interna: o modelo padrão de bloqueio (Standard Blocking Model - SBM), o qual assume que aquelas moléculas são adsorvidas nas paredes do poro, deste modo reduzindo seu diâmetro efetivo e o modelo de bloqueio do poro (Pore Blocking Model - 
PBM), o qual assume que aquelas moléculas ou seus agregados bloqueiam completamente alguns dos poros enquanto deixa os outros inalterados. Estes dois fenômenos ocorrem simultaneamente durante a filtração. Moléculas podem reduzir os diâmetros dos poros maiores e bloquear os poros menores ao mesmo tempo. Modelo de filtração de camada (Cake Filtration Model - CFM) descreve a incrustação externa. Este modelo assume que o agente filtrado (célula, restos de células e agregados) forma uma camada na superfície da membrana e a resistência cresce gradualmente. As duas etapas de incrustação podem ser experimentalmente diferenciadas pelo gráfico da resistência total por tempo. Incrustações internas (SBM ou PBM) são caracterizadas por uma curva côncava para cima, enquanto as externas (CFM) por uma curva côncava para baixo (SCHÄFER et al, 2000).

Partículas muito menores que os poros da membrana podem se depositar interiormente, o qual eventualmente conduz ao fechamento do poro. Partículas de um tamanho semelhante ao poro causarão bloqueio deste e partículas maiores que os poros se depositarão como uma camada, com a porosidade dependendo do tamanho da partícula. $\mathrm{O}$ fechamento do poro interno pode ser um processo lento comparado com o do poro obstruído, onde uma única partícula pode bloquear completamente um poro.

Partículas microscópicas são transportadas preferencialmente para a membrana através do movimento lento permeável. Para agregados, a sua densidade e estrutura poderiam fazer um papel importante. A rápida agregação (difusão limitada) resulta em uma estrutura muito aberta comparada a uma estrutura mais densa formada em uma lenta agregação (reação limitada). Schmitz et al. (1993) modelaram a agregação de partículas à superfície da membrana e acharam um espaço preenchido na camada para partículas que são arrastadas novamente devido ao fluxo de cisalhamento tangencial.

Estudos detalhados nos mecanismos de incrustações em membranas orgânicas causados por polissacarídeos e polifenóis são relativamente escassos. Belleville et al. (1990, 1992) estudaram incrustações de uma membrana tubular inorgânica durante a microfiltração de vinho tinto e atribuíram esta incrustação, principalmente a polissacarídeos e polifenóis. Trabalhos recentes de Vernhet et al. (1997) incluíram adsorção de polissacarídeos e tanino na membrana em condições estáticas. Entretanto, é conhecido que estes resultados não podem ser extrapolados para condições dinâmicas durante a filtração por membrana. 
Devido à deposição das partículas na membrana, a concentração na alimentação diminui continuamente. Por consideração do equilíbrio da massa da partícula no sistema inteiro, é possível calcular a quantia de massa depositada.

Os três métodos seguintes se referem a medidas das espessuras da camada:

- Mudança da capacidade elétrica devido a uma camada de partícula

- Mudança da condutividade elétrica devido a uma camada de partícula

- Medida direta da densidade da camada.

O fenômeno de concentração de polarização é o maior fator limitante em vários processos de separação por membrana. O princípio básico da separação por membrana leva a uma acumulação das espécies retidas e um esgotamento dos componentes permeáveis na camada limite adjacente à membrana e isto causa um gradiente de concentração. A polarização dos componentes leva a uma diminuição na força motora disponível das espécies preferencialmente permeáveis através da membrana e um aumento para as espécies menos permeáveis. Este fato reduz a eficiência total da separação. Em operações com fase líquida, a concentração de polarização pode levar a uma incrustação da membrana devido a precipitação ou gelificação do componente retido em sua superfície membrana. Isto pode limitar severamente o fluxo e a seletividade. As figuras 2.7 e 2.8 mostram o perfil de concentração para os componentes preferencialmente permeáveis e os retidos, respectivamente, na camada limite.

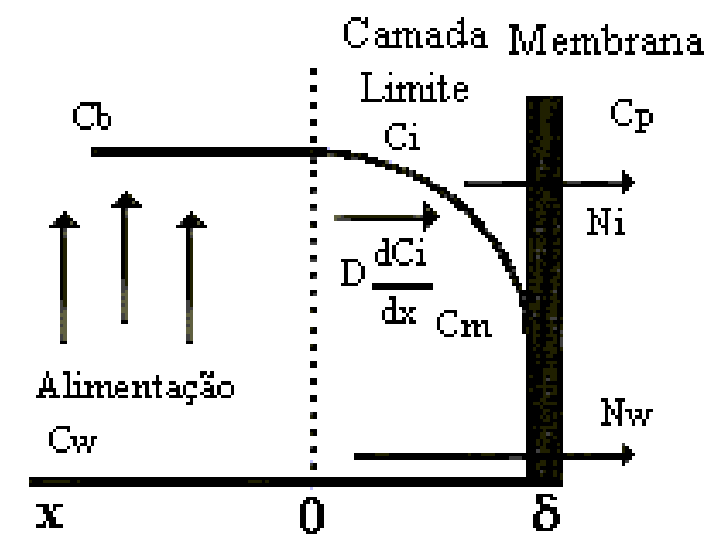

Figura 2.7: Perfil de concentração de componentes preferencialmente permeáveis sob regime permanente. 


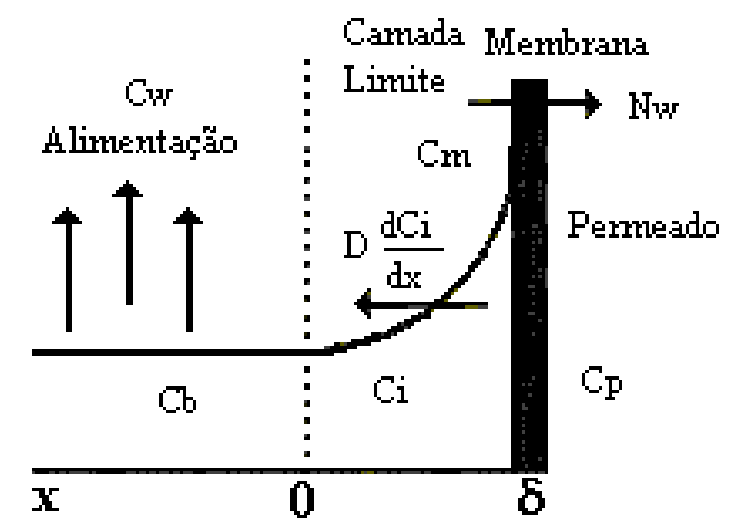

Figura 2.8: Perfil de concentração dos componentes retidos sob regime permanente.

A concentração de polarização (I) é definida como a razão da concentração do soluto na superfície da membrana $\left(\mathrm{C}_{\mathrm{m}}\right.$ ou $\left.\mathrm{x}_{\mathrm{m}}\right)$ com a concentração de soluto na alimentação $\left(\mathrm{C}_{\mathrm{b}}\right.$ ou $\left.\mathrm{x}_{\mathrm{b}}\right)$ :

$$
\mathrm{I} \equiv \frac{\mathrm{C}_{\mathrm{m}}}{\mathrm{C}_{\mathrm{b}}}=\frac{\mathrm{x}_{\mathrm{m}}}{\mathrm{x}_{\mathrm{b}}}
$$

Quanto mais esta razão (I) se afastar da unidade, maior será a polarização.

Nos casos de microfiltração, como o soluto começa a acumular perto da superfície da membrana, a difusão dos componentes do soluto começa ocorrer na direção oposta ao fluxo total de acordo com seu próprio gradiente de concentração. Em contraste, a concentração do solvente se mantém perto do constante em todo o sistema e deste modo não exibe nenhum gradiente de concentração significativo (BHATTACHARYA e HWANG, 1997).

A eficiência da separação dos processos de microfiltração é medida em termos da rejeição do soluto atingido. Assim, a polarização pode ser expressa como:

$$
I=\frac{e^{\mathrm{Pe}_{\mathrm{M}}}}{1+\left(1-\mathrm{r}_{\text {in }}\right)\left(\mathrm{e}^{\mathrm{Pe}_{\mathrm{M}}}-1\right)}
$$

onde $r_{i n}$ é a rejeição do soluto (propriedade intrínseca) e $\mathrm{Pe}_{\mathrm{M}}$ é o número de Peclet definido por:

$$
\mathrm{Pe}_{\mathrm{M}}=\frac{v \delta}{\mathrm{D}}
$$

onde $v$ é a velocidade, $\mathrm{D}$ a difusividade e $\delta$ é a espessura da camada limite.

Para a maioria dos processos de microfiltração, ultrafiltração e osmose reversa, a rejeição do soluto é normalmente muito alta e por este motivo tanto $r_{\text {in }}$ e $r \rightarrow 1$ 
resultam em uma rejeição quase perfeita. Assim simplificando a equação acima, o índice de polarização pode ser expresso como:

$$
\mathrm{I}=\mathrm{e}^{\mathrm{Pe}} \mathrm{M}
$$

A incrustação durante o processo de filtração por membrana é resultado de uma sequência complexa de eventos paralelos que se acumulam formando uma camada compacta na superfície da membrana, prejudicando seu desempenho. Não se sabe ao certo quais fatores afetam o processo de incrustação, porém há fundamentação na literatura de sua relação com forças eletrostáticas. Entretanto sabe-se que este fato reduz o fluxo e muda as características de separação da membrana, como a sua superfície química, a distribuição de carga na sua superfície, a hidrofobicidade e a receptividade para a deposição.

Sabe-se que controlar a deposição de soluto inicial pode potencialmente reduzir a incrustação a longo termo da membrana para solutos sensíveis. A ultrafiltração e microfiltração podem ser operadas em regime de baixa incrustação ou polarização controlando as condições de início, a pressão, concentração da parede ou fluxo durante a filtração tangencial.

O tipo do material da membrana, sua porosidade, a velocidade do fluxo e a pressão influem na formação da incrustação. Alguns parâmetros podem ser estáveis, como por exemplo, a vazão transmembrana que serve como indicação de quando a incrustação está ocorrendo e pode ser monitorado como uma função da pressão inicial imposta, com o aumento da taxa do fluxo e com a morfologia da membrana.

Modelos tradicionais de concentração de polarização são baseados no balanço de massa perto da parede da membrana. Os solutos na alimentação são transportados para a superfície da membrana por convecção e removidos por permeabilidade através da membrana ou por difusão dentro do núcleo do escoamento (CHEN, 1998).

Segundo Schluep e Widmer (1996), o parâmetro mais importante que influencia o fluxo da microfiltração tangencial é a relação entre a pressão transmembrana (TMP) e a tensão de cisalhamento na parede, $\tau_{\mathrm{w}}$. Na entrada do módulo o valor de $\mathrm{TMP} / \tau_{\mathrm{w}}$ é alto e muitas partículas são depositadas. Com o aumento do comprimento do módulo do filtro, a pressão transmembrana decresce uniformemente e alcança um mínimo na saída enquanto para pequenos fluxos de filtrado $\tau_{\mathrm{w}}$ é praticamente constante. Consequentemente este transporte convectivo de partículas para 
membrana é baixo na saída do módulo e menos partículas são depositadas (DE e BHATTACHARYA, 1996). 


\section{Materiais e Métodos}

\subsection{Agentes da Microfiltração}

Neste trabalho, utilizou-se como agentes no processo de microfiltração misturas de gomas Xantana e Guar em suspensão aquosa. Misturas puras e em diferentes concentrações foram produzidas para analisar a sinergia entre elas junto ao processo de concentração dos polissacarídeos.

As concentrações utilizadas foram: 100 ppm Xantana/900 ppm Guar, 900 ppm Xantana/100 ppm Guar, 250 ppm Xantana/750 ppm Guar, 750 ppm Xantana/250 ppm Guar, 500 ppm Xantana/500 ppm Guar, 1000 ppm Xantana e 1000 ppm Guar.

As gomas foram gentilmente cedidas pelo fornecedor Degussa (origem Francesa) e foram quantificadas as massas na balança Ohaus na relação volumétrica para 8 litros.

As misturas em suspensão de goma Xantana e Guar foram produzidas com água tratada de abastecimento a partir de agitação intensa num liquidificador, conduzindo a uma mistura homogênea em suspensão.

\subsection{Equipamento}

A Figura 3.1 apresenta o equipamento experimental utilizado no estudo do processo de microfiltração. O equipamento ofereceu versatilidade para investigar a variação dos principais parâmetros: pressão transmembrana; cisalhamento; regime de escoamento e temperatura. Observa-se na Figura 3.1 os principais elementos: tanque de parede dupla para armazenagem da mistura (1); uma bomba de deslocamento positivo (2) de vazão e pressão máxima de 500 1/h e $1200 \mathrm{kPa}$, respectivamente; rotâmetro (3); módulo para instalação dos meios filtrantes (4); inversor de freqüência (5) para controlar a rotação da bomba e sistema 
eletrônico com termopar para o controle de temperatura através da circulação de água no tanque de parede dupla; reservatório e bomba centrífuga (6) para circulação de água fria ou quente no tanque de parede dupla.

A pressão no módulo de filtração é controlada com um registro especial, tipo agulha, instalado no final do circuito hidráulico. Todos os elementos da bancada foram construídos em aço inox.

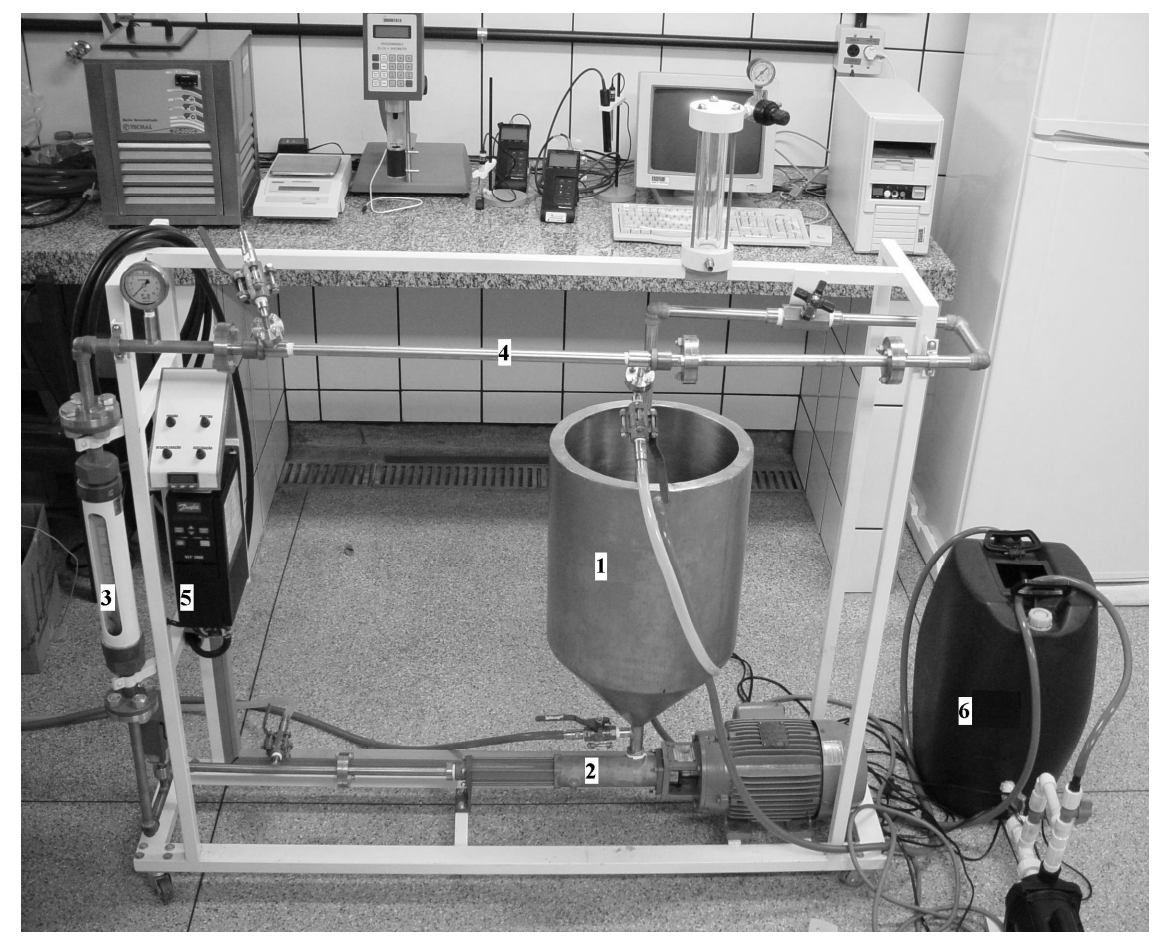

Figura 3.1. Foto do equipamento experimental. (1) - tanque de armazenagem da mistura; (2) - bomba de escoamento; (3) - rotâmetro; (4) - módulo com membrana; (5) - sistema de controle de aceleração da bomba e controle de temperatura; (6) - tanque de armazenagem de água fria ou quente.

No módulo de filtração foram inseridas membranas do tipo comercial importada ou na forma tubular microporosa nacional de alumina. As membranas de origem Alemã provenientes da Netzsch do Brasil possuem os seguintes valores nominais de tamanho de poro: $0,2 \mu \mathrm{m}, 40 \mathrm{~cm}$ de comprimento e $7 \mathrm{~mm}$ de diâmetro interno; 0,2 e 0,4 $\mu \mathrm{m}$ possuem 50 $\mathrm{cm}$ de comprimento e 5,9 $\mathrm{mm}$ de diâmetro interno. A membrana multicanal com tamanho nominal de poro de $0,2 \mu \mathrm{m}$, possui $1 \mathrm{~m}$ de comprimento e sete canais de 5,8 $\mathrm{mm}$ de diâmetro 
interno, cada um. No processo com a membrana multicanal, foram utilizados apenas dois canais dos sete existentes, para obter condições de escoamento, como a velocidade, próximas dos experimentos com as membranas monocanais. Para fechar os canais, colocouse cordões de silicone e tarugos de teflon para sua completa vedação. O meio tubular microporoso, a partir da análise de porosimetria de mercúrio apresentou predominantemente o tamanho nominal de poro de $0,3 \mu \mathrm{m}$.

A mistura fluida em estudo permaneceu em circulação a partir do tanque através de uma bomba de escoamento positivo, para se obter a concentração das suspensões macromoleculares. A pressão transmembrana foi mantida a $300 \mathrm{kPa}$ e o processo foi analisado através de medidas da vazão de permeado registradas em função do tempo durante no mínimo 36 minutos. Os experimentos foram conduzidos na temperatura ambiente, $25^{\circ} \mathrm{C}$ $\pm 0,5{ }^{\circ} \mathrm{C}$, por um banho termostatizado e circulante no tanque de alimentação encamisado. Foram feitos também experimentos a $40^{\circ} \mathrm{C} \pm 0,5^{\circ} \mathrm{C}$, para todas as misturas proporcionais de gomas Xantana e Guar, membranas e tubos microporosos. Os experimentos para as sete concentrações citadas acima e nas duas temperaturas em questão foram realizados a uma pressão de $300 \mathrm{KPa}$ e velocidade tangencial de $3,7 \mathrm{~m} / \mathrm{s}$. Verificou-se também o comportamento das misturas proporcionais nas membranas comerciais importadas, através de experimentos com variação de pressão e velocidade à $25^{\circ} \mathrm{C}$, para apenas três concentrações das gomas, 1000 ppm de Xantana, 1000 ppm de Guar e 500/500 ppm de cada uma. As pressões utilizadas foram de 300, 400 e $500 \mathrm{kPa}$. Para os tubos microporosos de origem nacional (C1T-, C2T-, C2T+, C3T+ e C4T+), produzidos pela CETEBRA - São Carlos/SP foram conduzidos experimentos a pressões de 300,400 e $500 \mathrm{kPa}$, à $25^{\circ} \mathrm{Cmas}$ apenas para Xantana a 1000 ppm. Através da vazão do concentrado que circulava no sistema pelo tempo, foi calculado uma média das velocidades no tubo circular. São elas: 2,6; 3,7; 4,7 e $5,7 \mathrm{~m} / \mathrm{s}$ para a membrana monocanal comercial e 1,5 e $3,3 \mathrm{~m} / \mathrm{s}$ para os tubos. 


\subsection{Propriedades Físicas e Químicas}

Para cada experimento foram medidas as seguintes propriedades físicas e químicas em tempos previamente estabelecidos: vazão, condutividade elétrica, $\mathrm{pH}$, densidade, Carbono Orgânico Total (Total Organic Carbon - TOC), absorbância e viscosidade. A vazão foi medida apenas para o permeado, a condutividade, o $\mathrm{pH}$, a densidade, o TOC e a absorbância foram medidos tanto para concentrado quanto para filtrado, já a viscosidade foi medida apenas para o concentrado. A condutividade elétrica apresenta valores em micro Siemens $(\mu \mathrm{S})$ realizados no equipamento Orion, modelo 115 , o $\mathrm{pH}$ também foi medido no equipamento Orion, modelo 290 e a vazão do permeado foi calculada em $1 /\left(\mathrm{h}_{\mathrm{m}} \mathrm{m}^{2}\right)$. A densidade foi obtida por um picnômetro de $25 \mathrm{ml}$ e o TOC foi medido no equipamento Shimadzu - 5000 A.

Pode-se observar na Figura 3.1 os equipamentos utilizados para a investigação das propriedades físicas; da esquerda para a direita tem-se respectivamente, banho térmico; balança de precisão; reômetro; medidores de $\mathrm{pH}$ e condutividade elétrica.

\subsubsection{Comportamento Reológico}

Antes de submeter as suspensões ao processo de microfiltração, realizou-se análises do comportamento reológico das misturas puras e proporcionais das gomas Xantana e Guar.

As medidas foram feitas em um reômetro de cilindros concêntricos da Brookfield, modelo DV-III+, com a finalidade de observar se a sinergia das misturas proporcionais citadas no item 3.1 modificava a estrutura da solução aquosa, ou seja, sua provável ocorrência de formação de gel. Os experimentos foram conduzidos em duas temperaturas, $25^{\circ} \mathrm{C}$ e $40^{\circ} \mathrm{C}$, por um banho termostatizado e circulante no recipiente da amostra.

As curvas de tensão de cisalhamento $(\tau)$ em função da taxa de deformação $(\dot{\gamma})$, foram ajustadas com o modelo de Lei de Potência, devido às suspensões apresentarem comportamento de fluido pseudoplástico. 


\subsubsection{Espectrometria no Infravermelho}

A radiação no infravermelho corresponde à parte do espectro situada entre as regiões do visível e das microondas. A faixa mais importante para análise do composto orgânico está entre 4000 e $400 \mathrm{~cm}^{-1}$. O infravermelho é característico da molécula como um todo, mas alguns grupos de átomos originam bandas que ocorrem mais ou menos na mesma frequência, independente da estrutura da molécula. Através destas bandas são feitas análises do espectro, consultas em tabelas e de outras informações necessárias, obtendo assim a identificação das estruturas. (SILVERSTEIN, 1979).

Uma análise foi realizada com a técnica de absorbância no espectômetro de infravermelho com transformada de Fourier (Equipamento Perkin Elmer - modelo Paragon 1000) no permeado final, no concentrado inicial e no concentrado final, para verificar se houve a passagem das gomas pela membrana. Analisou-se qualitativamente os espectros através da normalização das curvas para verificar se houve uma desestruturação das moléculas das gomas. A técnica utilizada foi a reflexão total atenuada (ATR) ou espectroscopia de reflexão interna que permite a obtenção de espectros qualitativos.

Essa análise foi realizada para as misturas puras e proporcionais das gomas para as membranas monocanais de $0,2 \mu \mathrm{m}$ a $40^{\circ} \mathrm{C}$ e $0,4 \mu \mathrm{m}$ a $25^{\circ} \mathrm{C}$ e $40^{\circ} \mathrm{C}$, na pressão de $300 \mathrm{kPa}$ e velocidade média de $3,7 \mathrm{~m} / \mathrm{s}$. Foi realizada também na membrana monocanal de $0,4 \mu \mathrm{m}$ à $25^{\circ} \mathrm{C}$, variando a pressão e a velocidade ( $\mathrm{P}=300,400,500 \mathrm{kPa} ; \mathrm{u}=2,6 ; 3,7 ; 4,7 ; 5,7 \mathrm{~m} / \mathrm{s}$ ). O espectro no infravermelho foi obtido também para os tubos microporosos, aqui denominados por C4T+, C1T-, C3T-, C2T-e C2T+, à $25^{\circ} \mathrm{C}$ para apenas goma Xantana e com variação da pressão e velocidade média respectivamente: $\mathrm{P}=300,400$ e $500 \mathrm{kPa}$ e u $=$ 1,5 e $3,3 \mathrm{~m} / \mathrm{s}$. O meio microporoso dos tubos especificados acima foram caracterizados pela técnica de intrusão de mercúrio quanto ao tamanho médio dos poros. As respectivas curvas característica de porosimetria são apresentadas no Anexo D.

Pode-se analisar os gráficos da intensidade das bandas pelo comprimento de onda em função da transmitância ou da absorbância. A transmitância é a razão entre a energia radiante transmitida por uma amostra e a energia radiante que nela incide. A absorbância é o logaritmo, na base 10, do inverso da transmitância $\left[\mathrm{A}=\log _{10}(1 / \mathrm{T})\right]^{1}$ (SILVERSTEIN, 1979). 
A Tabela 3.1 mostra que as frequências de deformação axial das ligações possuem as seguintes regiões de absorção.

Tabela 3.1: Região de absorção em diferentes tipos de ligações.

\begin{tabular}{|c|c|}
\hline Tipo de Ligação & Região de Absorção \\
\hline $\mathrm{C}-\mathrm{C}, \mathrm{C}-\mathrm{O}, \mathrm{C}-\mathrm{N}$ & $1300-800$ \\
\hline $\mathrm{C}=\mathrm{C}, \mathrm{C}=\mathrm{O}, \mathrm{C}=\mathrm{N}, \mathrm{N}=\mathrm{O}$ & $1900-1500$ \\
\hline $\mathrm{C} \equiv \mathrm{C}, \mathrm{C} \equiv \mathrm{N}$ & $2300-2000$ \\
\hline $\mathrm{C}-\mathrm{H}, \mathrm{O}-\mathrm{H}, \mathrm{N}-\mathrm{H}$ & $3800-2700$ \\
\hline
\end{tabular}

Para os concentrados finais e iniciais e os permeados finais de cada experimento foram construídos gráficos de absorbância por comprimento de onda $\left(4000\right.$ a $\left.400 \mathrm{~cm}^{-1}\right)$. A unidade $\mathrm{cm}^{-1}$ é proporcional à energia de vibração, sendo os números de ondas o inverso do comprimentos de onda $\left(\mathrm{cm}^{-1}=10^{4} / \mu \mathrm{m}\right)$.

\subsection{Limpeza do Equipamento}

Inicialmente, entre cada experimento, as membranas foram submetidas ao seguinte procedimento de limpeza: 5 minutos em circulação de água tratada, 10 minutos com solução de detergente neutro, 5 minutos de água tratada, 5 minutos com solução a base de $\mathrm{NaOH}$ e novamente 5 minutos de água tratada.

Posteriormente foi utilizada uma solução de detergente enzimático MIX UF10 da Mixing Química Ind. Com. (Santa Branca, SP). Este procedimento foi satisfatório para a recuperação da vazão transmembrana e início de outros experimentos. 